\title{
Diagnostic performance of imaging modalities in chronic pancreatitis: a systematic review and meta-analysis
}

\author{
Y. Issa ${ }^{1}$ - M. A. Kempeneers ${ }^{1}$ - H. C. van Santvoort ${ }^{1}$ - T. L. Bollen ${ }^{2}$ - S. Bipat ${ }^{3}$ • \\ M. A. Boermeester ${ }^{1}$
}

Received: 3 May 2016/Revised: 20 September 2016 / Accepted: 16 December 2016/Published online: 27 January 2017

(C) The Author(s) 2017. This article is published with open access at Springerlink.com

\begin{abstract}
Objectives Obtain summary estimates of sensitivity and specificity for imaging modalities for chronic pancreatitis (CP) assessment.

Methods A systematic search was performed in Cochrane Library, MEDLINE, Embase and CINAHL databases for studies evaluating imaging modalities for the diagnosis of CP up to September 2016. A bivariate random-effects modeling was used to obtain summary estimates of sensitivity and specificity.

Results We included 43 studies evaluating 3460 patients. Sensitivity of endoscopic retrograde cholangiopancreatography (ERCP) $(82 \%$; 95\%CI: 76\%-87\%) was significant higher than that of abdominal ultrasonography (US) $(67 \%$; 95\%CI: 53\%$78 \% ; \mathrm{P}=0.018)$. The sensitivity estimates of endoscopic ultrasonography (EUS), magnetic resonance imaging (MRI), and computed tomography (CT) were $81 \%$ (95\%CI: 70\%-89\%), $78 \%$ (95\%CI: 69\%-85\%), and 75\% (95\%CI: 66\%-83\%), respectively, and did not differ significantly from each other. Estimates of specificity were comparable for EUS (90\%; 95\% CI: 82\%-95\%), ERCP (94\%; 95\%CI: 87\%-98\%), CT (91\%; 95\% CI: 81\%96\%), MRI (96\%; 95\%CI: 90\%-98\%), and US (98\%; 95\%CI: 89\%-100\%).

Conclusions EUS, ERCP, MRI and CT all have comparable high diagnostic accuracy in the initial diagnosis of CP. EUS
\end{abstract}

M. A. Boermeester

m.a.boermeester@amc.uva.nl

1 Department of Surgery, Academic Medical Centre, Meibergdreef 9, 1100DD Amsterdam, The Netherlands

2 Department of Radiology, St Antonius Ziekenhuis, Koekoekslaan 1, 3430EM Nieuwegein, The Netherlands

3 Department of Radiology, Academic Medical Centre, Meibergdreef 9, 1100DD Amsterdam, The Netherlands and ERCP are outperformers and US has the lowest accuracy. The choice of imaging modality can therefore be made based on invasiveness, local availability, experience and costs.

Key Points

- EUS, ERCP, MRI and CT have high diagnostic sensitivity for chronic pancreatitis

- Diagnostic specificity is comparable for all imaging modalities

- EUS and ERCP are outperformers and US has the lowest accuracy

- The choice of imaging can be made based on clinical considerations

Keywords Chronic pancreatitis · Diagnostic imaging · Diagnostic accuracy $\cdot$ Meta-analysis

\section{Introduction}

Chronic pancreatitis (CP) is a disabling inflammatory disease of the pancreas characterized by severe recurrent or continuous abdominal pain and considerable impact on the quality of life [1-4]. Patients with CP usually develop endocrine and exocrine insufficiency during the course of the disease as a result of the progressive loss of pancreatic parenchyma.

There is lack of international consensus regarding the initial diagnosis of $\mathrm{CP}$, particularly at its early stages. The diagnosis is often made by a combination of clinical symptoms (e.g. abdominal pain, malabsorption, diabetes mellitus), pancreatic function tests (e.g. fecal elastase-1) and morphological abnormalities seen on imaging (e.g. calcifications, ductal lesions, pseudocysts) [5, 6]. Imaging plays a key role in the diagnosis and therapeutic management of patients with $\mathrm{CP}$. The most frequently used imaging modalities for $\mathrm{CP}$ are endoscopic ultrasonography (EUS), endoscopic retrograde 
cholangiopancreatography (ERCP), magnetic resonance imaging (MRI), computed tomography (CT) and ultrasonography (US).

The aim of this meta-analysis was to determine the diagnostic accuracy of imaging modalities for the initial diagnostic assessment of CP.

\section{Methods}

\section{Search}

A search was performed in Cochrane Library, MEDLINE, EMBASE and CINAHL databases, without restrictions for publication date or language up to September 2016. The search included terms for chronic pancreatitis, EUS, ERCP, MR imaging, CT and US. For detailed search details, see Appendix Table 5.

\section{Selection of studies}

All search hits were screened on title and abstract and eligible articles on full text by two reviewers independently (YI and MAK). Disagreements were solved through discussion with a third reviewer (MAB). Studies were eligible when EUS, ERCP, MR imaging, CT or US was evaluated in patients with suspected CP. Duplicates, reviews, letters, case reports and book chapters were excluded. The remaining studies were potentially eligible and their full text was retrieved. To identify additional relevant studies, the reference lists of the included studies were checked manually. Studies were included if they met the following criteria: (1) sufficient data was reported to construct $2 \times 2$ tables (true positive, false positive, true negative and false negative); (2) the imaging technique was compared with a reference standard (e.g. surgery, histology, follow-up). Exclusion criteria were: (1) evaluation of imaging techniques other than the aforementioned (e.g. PET-CT, EUS-FNA, EUS-elastography); (2) imaging techniques used for treatment of patients with CP (e.g. therapeutic ERCP, EUS-guided pseudocyst drainage); (3) in vitro studies; (4) studies that included less than five patients with CP; (5) studies where no separate analysis were done for patients with CP; and (6) full-text articles that were not available or retrievable.

\section{Data extraction and critical appraisal}

Data was extracted systematically from the included studies by using a structured study record form. The following study design and patient characteristics were extracted: name of the first author, country of origin, year of publication, name of journal, study design, total number of patients included, number of included patients with $\mathrm{CP}$, median or mean age, the proportion of male patients, and the patient inclusion criteria.
Data was extracted regarding the imaging characteristics: type of imaging modality, scoring criteria, technical features for each modality, and reported observer experience. Also data on the reference standard was extracted, such as clinical follow-up, surgery and histology.

The methodological quality of the included articles was assessed by the Quality Assessment of Diagnostic Accuracy Studies version 2 (QUADAS-2) tool [7]. The QUADAS-2 tool evaluates the risk of bias in four domains (patient selection, index test, reference standard, flow and timing) and the clinical applicability in the first three domains. Signaling questions were used to help assess the risk of bias and applicability. Possible answers were 'yes', 'no' or 'unclear' in which 'yes' indicates no risk of bias. In addition the GRADE scoring system for diagnostic tests was used, which assesses the quality of evidence for each imaging modality [8, 9]. Although the criteria are applicable to diagnostic test accuracy, the methods are less well established compared to interventional studies [10]. Two reviewers independently (YI and MAK) assessed the QUADAS-2 and the GRADE scoring system and all disagreements were resolved by reaching consensus.

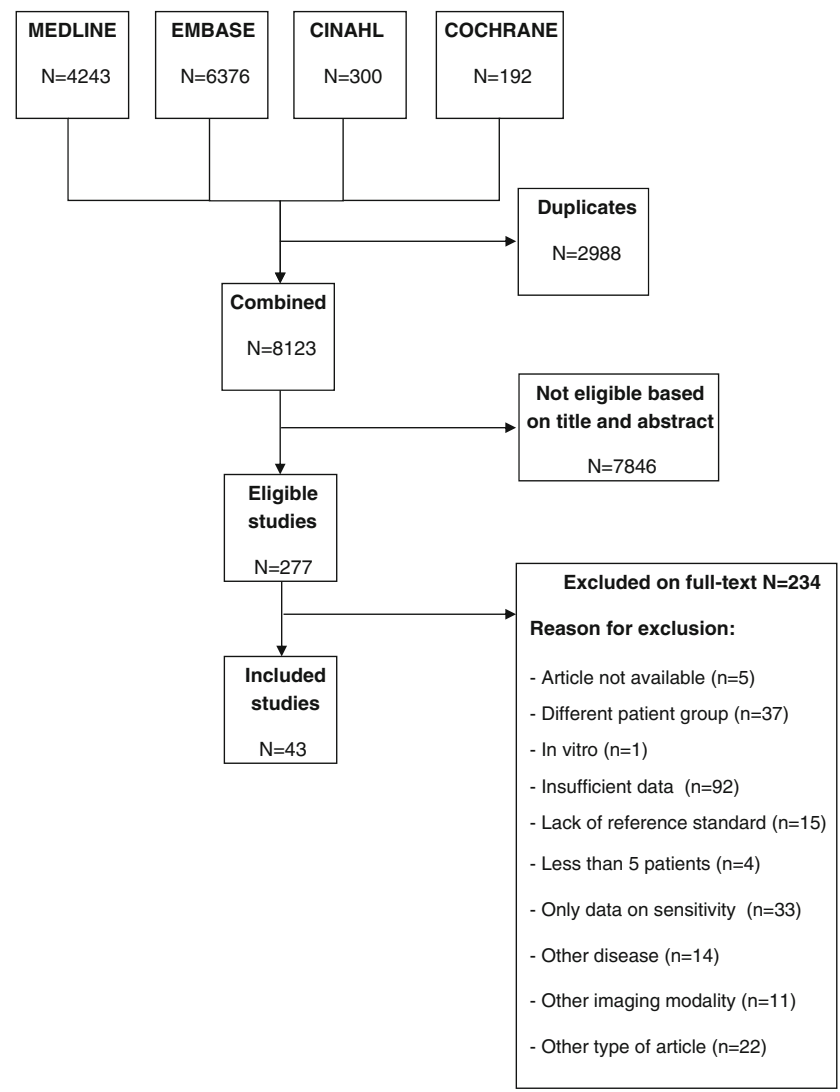

Fig. 1 Flow chart 


\section{Data analysis}

\section{Overall diagnostic accuracy}

For each included study we constructed a $2 \times 2$ contingency table for each imaging modality. If diagnostic accuracy was compared between different observers, mean values were calculated. Sensitivity and specificity estimates, the positive predictive value and negative predictive values, and the accuracy were calculated from the reconstructed contingency tables. We used the $I^{2}$ test with $95 \%$ confidence interval $(95 \%$ CI) to quantify heterogeneity [11]. Mean logit sensitivity and specificity were acquired, and the anti-logit transformation was then obtained to calculate summary estimates of

Table 1 Study characteristics of included studies

\begin{tabular}{|c|c|c|c|c|c|c|}
\hline Study & Year & Country & $\mathrm{P} / \mathrm{R}$ & $\mathrm{OE}$ & Modality & Reference standard for CP diagnosis \\
\hline Adamek et al & 2000 & Germany & $\mathrm{P}$ & No & $\mathrm{MRCP} / \mathrm{ERCP}$ & Histology (NA), FU (NA) \\
\hline Albashir et al & 2010 & USA & $\mathrm{R}$ & Yes & EUS & Histology (all) \\
\hline Alcaraz et al & 2000 & Spain & $\mathrm{P}$ & Yes & MRCP & Surgery (4), ERCP (70), PTC (7) \\
\hline Balci et al & 2006 & USA and Germany & $\mathrm{R}$ & No & MRCP & ePFT (all) \\
\hline Bolog et al & 2004 & Romania & $\mathrm{R}$ & No & MRCP & Surgery (NA), ERCP (NA), FU (NA) \\
\hline Brand et al & 2000 & Germany & $\mathrm{P}$ & No & EUS & Histology (all) \\
\hline Buscail et al & 1995 & France & $\mathrm{P}$ & No & $\begin{array}{l}\text { US/CT/ERCP } \\
\quad / \text { EUS }\end{array}$ & $\begin{array}{l}\text { Histology ( } 7) \text {, morphological } \\
\text { changes (i.e. calcifications) and } \\
\text { exocrine insufficiency (42) + FU (all) }\end{array}$ \\
\hline Catalano et al & 1998 & USA & $\mathrm{P}$ & No & EUS & $\mathrm{ERCP}+\mathrm{ePFT}($ all $)$ \\
\hline Chong et al & 2007 & USA & $\mathrm{R}$ & Yes & EUS & Surgery (all) \\
\hline Conwell et al & 2007 & USA & $\mathrm{R}$ & Yes & EUS & ePFT (all) \\
\hline Dramaix et al & 1980 & France & $\mathrm{P}$ & No & $\mathrm{US} / \mathrm{CT}$ & Surgery (NA), ERCP (NA) \\
\hline Fusari et al & 2010 & Italy & $\mathrm{P}$ & Yes & CT/MRCP & Biopsy (33), histology (7) \\
\hline Gebel et al & 1985 & Germany & $\mathrm{P}$ & No & US/ERP & Obduction (NA), Surgery (NA), FU (NA) \\
\hline Giovannini et al & 1994 & France & $\mathrm{P}$ & No & EUS & ERCP (all) \\
\hline Glasbrenner et al & 2000 & Germany & $\mathrm{P}$ & Yes & EUS/ERCP & Surgery (all) \\
\hline Gmelin et al & 1981 & Germany & $\mathrm{P}$ & No & $\mathrm{US} / \mathrm{CT} / \mathrm{ERCP}$ & Surgery (NA)+FU (NA) \\
\hline Hellerhoff et al & 2002 & Germany & $\mathrm{P}$ & Yes & MRCP/sMRCP & ERCP (35), surgery (4), FU (56) \\
\hline Imdahl et al & 1999 & Germany & $\mathrm{P}$ & Yes & $\mathrm{CT}$ & Histology (42), FU (6) \\
\hline Kremer et al & 1977 & Germany & $\mathrm{R}$ & No & US & $\begin{array}{l}\text { Clinical diagnosis (338), ERCP, surgery, } \\
\text { ePFT, angiography (NA) }\end{array}$ \\
\hline Lammer et al & 1980 & Germany & $\mathrm{R}$ & No & $\mathrm{ERCP} / \mathrm{CT}$ & $\begin{array}{l}\text { Surgery (31), angiography (16), } \\
\text { clinical diagnosis }(60)\end{array}$ \\
\hline Lawson et al & 1978 & USA & $\mathrm{R}$ & Yes & ERCP/US & Surgery $(25), \mathrm{FU}(50)$ \\
\hline Lees et al & 1979 & UK & $\mathrm{P}$ & No & US & Surgery (36), ERCP (46) \\
\hline Lin et al & 1989 & Taiwan & $\mathrm{R}$ & No & US/EUS & Histology (26), CT (4), surgery+ERCP (3) \\
\hline Nattermann et al & 1993 & Germany & $\mathrm{P}$ & No & EUS & ERCP (94), FU (20) \\
\hline Pamos et al & 1998 & Spain & $\mathrm{P}$ & Yes & MRCP & ERCP (all) \\
\hline Parsi et al & 2008 & USA & $\mathrm{R}$ & Yes & ERCP & FU (all) \\
\hline Pistolesi et al & 1981 & Italy & $\mathrm{P}$ & No & $\mathrm{CT}$ & Surgery (all) \\
\hline Pungpapong et al & 2007 & USA & $\mathrm{P}$ & Yes & EUS & $\begin{array}{l}\text { Clinical history, lab data, ERCP/CT/MRI } \\
\text { and/or surgical pathology (all) }\end{array}$ \\
\hline Pungpapong et al & 2007 & USA & $\mathrm{P}$ & Yes & MRCP/EUS & ERCP (48), surgery (9), FU (57) \\
\hline Rudowicz-Pietruszewska et al & 2002 & Poland & $\mathrm{P}$ & No & MRCP & ERCP (all) \\
\hline Sai et al & 2008 & Japan & $\mathrm{P}$ & Yes & SMRCP & ERCP (all) \\
\hline Savarino et al & 1980 & Italy & $\mathrm{R}$ & No & $\mathrm{CT}$ & Surgery (NA), calcifications (NA), clinical and lab data (NA) \\
\hline Scarabino et al & 1989 & Italy & $\mathrm{R}$ & No & ERCP, US, CT & Combination of CT, US and ERCP (all) \\
\hline Schlaudraff et al & 2008 & USA and Germany & $\mathrm{P}$ & Yes & $\mathrm{MRCP} / \mathrm{sMRCP}$ & Clinical history, laboratory, radiology ( $\geq 2$ methods) (all) \\
\hline Stevens et al & 2009 & USA & $\mathrm{P}$ & Yes & EUS & ePFT (all) \\
\hline Sverko et al & 2011 & Croatia & $\mathrm{R}$ & No & MRCP & Histology (all) \\
\hline Swobodnik et al & 1983 & Germany & $\mathrm{P}$ & No & $\mathrm{US} / \mathrm{CT} / \mathrm{ERCP}$ & FU (59), surgery (22) \\
\hline Tox et al & 2007 & Germany & $\mathrm{R}$ & Yes & EUS & Surgery (79), FU (92) \\
\hline Trikudanathan et al & 2016 & USA & $\mathrm{R}$ & YES & EUS & Histology (all) \\
\hline Triller et al & 1975 & Switzerland & $\mathrm{P}$ & No & ERCP & Surgery (14), autopsy (1), FU (9) \\
\hline Wiersema et al & 1993 & USA & $\mathrm{P}$ & No & EUS/ERCP & FU (51), ePFT (16) \\
\hline Zhang et al & 2003 & USA & $\mathrm{R}$ & No & MRCP & US (12), CT (11), ERCP (6) \\
\hline Zuccaro et al & 2009 & USA & $\mathrm{R}$ & No & MRCP/sMRCP & ePFT (all) \\
\hline
\end{tabular}

$P$ prospective, $R$ retrospective, $O E$ observer experience reported, $P T C$ percutaneous transhepatic cholangiogram, $e P F T$ endoscopic pancreatic function test, $F U$ follow-up, $N A$ not available 
sensitivity and specificity with $95 \%$ CIs. Forest plots were made to visualize the sensitivity and specificity with the 95\% CIs. Summary estimates of sensitivity and specificity, including $95 \% \mathrm{CI}$, were obtained by using a random-effects model [12]. In cases where a negative covariance between the logit sensitivity and logit specificity was obtained, summary receiver operating characteristic curve (sROC) were generated for each separate imaging modality. We used the $z$ test to

Table 2 Patient characteristics of included studies

\begin{tabular}{|c|c|c|c|c|c|}
\hline Study & $\mathrm{Nr}$ pts & Age & Male $(\%)$ & $\mathrm{Nr}$ pts $\mathrm{CP}$ & Patient selection \\
\hline Adamek et al & 124 & 55 & $61 \%$ & 57 & Suspected pancreatic mass (clinical presentation, lab, US) \\
\hline Albashir et al & 23 & $43^{*}$ & $57 \%$ & 19 & Suspected chronic pancreatitis (clinical presentation) \\
\hline Alcaraz et al & 81 & $65^{* *}$ & $31 \%$ & 8 & Suspected pancreatobiliary disease (clinical presentation, US) \\
\hline Balci et al & 30 & $48^{*}$ & $17 \%$ & 11 & Suspected early CP (clinical presentation) \\
\hline Bolog et al & 103 & $57^{*}$ & $43 \%$ & 15 & Suspected pancreatobiliary disease (US/CT or clinical presentation) \\
\hline Brand et al & 115 & $61^{*}$ & $59 \%$ & 24 & $\begin{array}{l}\text { Suspected focal pancreatic lesion (US/CT/ERCP or lab/tumour } \\
\text { markers) }\end{array}$ \\
\hline Buscail et al & 62 & $50 *$ & $79 \%$ & 44 & $\begin{array}{l}\text { Suspected chronic pancreatitis (clinical presentation, } \\
\text { lab, imaging) }\end{array}$ \\
\hline Catalano et al & 80 & $51^{*}$ & $40 \%$ & 38 & Non-alcoholic recurrent acute pancreatitis (3-11 episodes) \\
\hline Chong et al & 71 & $45^{*}$ & $46 \%$ & 64 & Suspected chronic pancreatitis (clinical presentation) \\
\hline Conwell et al & 56 & $44 *$ & $45 \%$ & 38 & Suspected chronic pancreatitis (clinical presentation) \\
\hline Dramaix et al & 50 & $52 *$ & $66 \%$ & 18 & Suspected pancreatic disease (clinical presentation) \\
\hline Fusari et al & 40 & $62 *$ & $55 \%$ & 8 & Suspected pancreatic mass (clinical presentation and US) \\
\hline Gebel et al & US: 56, ERP: 45 & NA & NA & US: 22, ERP: 16 & Suspected pancreatic disease (clinical presentation) \\
\hline Giovannini et al & 26 & NA & NA & 17 & $\begin{array}{l}\text { Suspected pancreatobiliary disease (clinical } \\
\text { presentation, imaging/lab) }\end{array}$ \\
\hline Glasbrenner et al & 85 & NA & NA & 41 & Suspected pancreatic mass (clinical presentation, US/CT) \\
\hline Gmelin et al & 41 & $54 *$ & $68 \%$ & 19 & Suspected pancreatic disease (clinical presentation) \\
\hline Hellerhoff et al & 95 & NA & NA & 26 & Suspected pancreatic disease (clinical presentation) \\
\hline Imdahl et al & 48 & $58 *$ & $60 \%$ & 12 & Suspected pancreatic disease (clinical presentation) \\
\hline Kremer et al & 446 & NA & NA & 61 & Suspected pancreatic disease (clinical presentation) \\
\hline Lammer et al & 107 & NA & NA & 39 & Suspected pancreatic disease (clinical presentation) \\
\hline Lawson et al & 75 & NA & NA & 26 & Suspected pancreatic disease (clinical presentation) \\
\hline Lees et al & 98 & NA & NA & 20 & Suspected pancreatic disease (clinical presentation) \\
\hline Lin et al & 33 & $47^{*}$ & $58 \%$ & 7 & Suspected pancreatic disease (clinical presentation) \\
\hline Nattermann et al & 114 & $53^{*}$ & $67 \%$ & 51 & Suspected pancreatic disease (clinical presentation) \\
\hline Pamos et al & 41 & $64 *$ & $59 \%$ & 5 & Suspected pancreatobiliary disease (clinical presentation) \\
\hline Parsi et al & 35 & $46^{* *}$ & $46 \%$ & 24 & Suspected chronic pancreatitis (clinical presentation) \\
\hline Pistolesi et al & 100 & NA & NA & 31 & Suspected pancreatic disease (clinical presentation) \\
\hline Pungpapong et al & 79 & $50 * *$ & $35 \%$ & 38 & Suspected chronic pancreatitis (clinical presentation) \\
\hline Pungpapong et al & 99 & $55^{* *}$ & $41 \%$ & 40 & Suspected chronic pancreatitis (clinical presentation) \\
\hline Rudowicz-Pietruszewska et al & 88 & $52 *$ & $64 \%$ & 9 & $\begin{array}{l}\text { Suspected pancreatobiliary disease (clinical presentation, } \\
\text { lab, US/CT) }\end{array}$ \\
\hline Sai et al & 28 & $36^{*}$ & NA & 16 & Mild chronic pancreatitis (ERCP) \\
\hline Savarino et al & 108 & $47 * *$ & $67 \%$ & 59 & Suspected pancreatic disease (clinical presentation) \\
\hline Scarabino et al & 63 & $44 * *$ & $63 \%$ & 12 & Suspected of biliopancreatic disease (clinical presentation) \\
\hline Schlaudraff et al & 62 & NA & NA & 9 & Suspected chronic pancreatitis (clinical presentation) \\
\hline Stevens et al & 100 & NA & $38 \%$ & 41 & Suspected chronic pancreatitis (clinical presentation) \\
\hline Sverko et al & 29 & $44 * *$ & $52 \%$ & 14 & Suspected pancreatic disease (clinical presentation) \\
\hline Swobodnik et al & 81 & $49^{*}$ & $52 \%$ & 27 & Suspected pancreatic disease (clinical presentation) \\
\hline Tox et al & 171 & $61^{*}$ & NA & 65 & Suspected pancreatic disease (clinical presentation) \\
\hline Trikudanathan et al & 68 & $39^{*}$ & $18 \%$ & 56 & Total pancreatectomy for non-calcific chronic pancreatitis \\
\hline Triller et al & 24 & $52 *$ & $83 \%$ & 11 & Suspected pancreatobiliary disease (clinical presentation) \\
\hline Wiersema et al & 67 & $45^{*}$ & $20 \%$ & 30 & Suspected pancreatobiliary disease (clinical presentation) \\
\hline Zhang et al & 44 & $50 *$ & $30 \%$ & 24 & $\begin{array}{l}\text { Suspected early or mild chronic pancreatitis (clinical } \\
\text { presentation, US/CT/ERCP) }\end{array}$ \\
\hline Zuccaro et al & 69 & $43 *$ & $35 \%$ & 28 & Suspected chronic pancreatitis (clinical presentation) \\
\hline
\end{tabular}

$N A$ not available

* Mean

**Median 
Fig. 2 Summary of study quality (QUADAS-2)

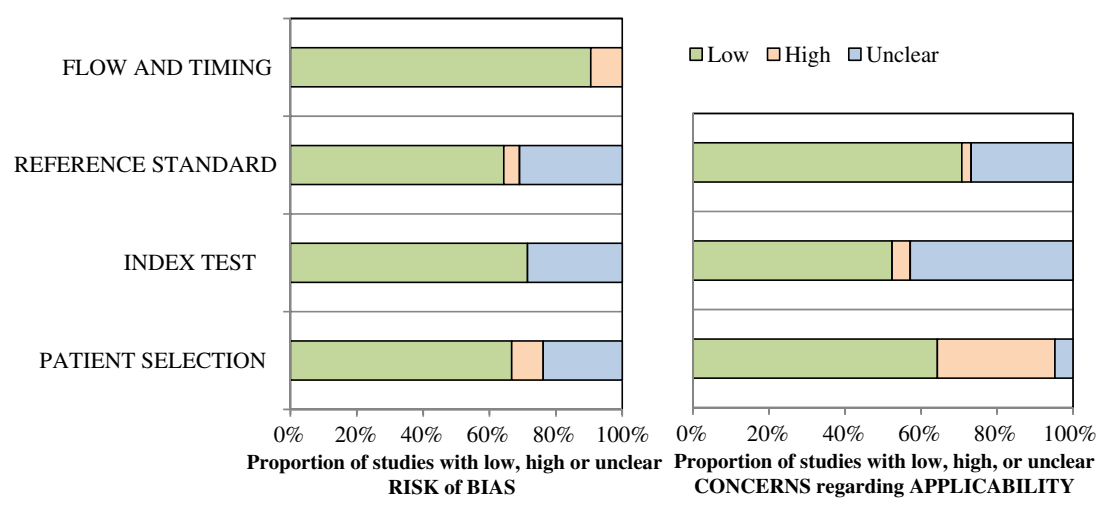

evaluate differences in sensitivity and specificity between the five imaging modalities. A $p$ value of less than 0.05 indicated a statistically significant difference.

\section{Heterogeneity exploration}

The following factors were incorporated in the bivariate model and we evaluated the effect on the sensitivity and specificity, and cause of heterogeneity for all imaging modalities according to the QUADAS-2 tool: clear description of criteria for bias (low bias versus high bias or unclear) for (a) patient selection, (b) criteria for the index test used, (c) sufficient description and verification with the reference standard, and (d) the flow and timing.

\section{Head to head comparison}

A head to head comparison was performed in studies that compared the diagnostic accuracy of two or more imaging modalities. Heterogeneity was quantified by $I^{2}$ test, with $95 \%$ CI. The random-effects $\left(I^{2}>25 \%\right)$ and fixed effects $\left(I^{2}\right.$ $\leq 25 \%$ ) models were used to obtain summary estimates of sensitivity and specificity, and compared with one another by a paired $z$ test.

For data analysis, Review Manager (RevMan, version 5.3. Copenhagen: The Cochrane Collaboration, 2014) and SAS (version 9.3; SAS Institute, Cary, NC) were used. We adhered to the Preferred Reporting Items for Systematic Reviews and Meta-Analyses (PRISMA) guidelines [13].

\section{Results}

\section{Study selection}

The initial search resulted in 11,111 hits, of which 2988 duplicates were removed, resulting in a total of 8123 titles and abstracts that were screened for eligibility. The full text of 277 articles was retrieved; 43 of these articles fulfilled the inclusion criteria. See Appendix Table 6 for the excluded articles. Figure 1 shows the flow chart of the search.

\section{Study and patient characteristics}

Study characteristics, including the reference standard for the diagnosis of CP for each included study, are listed in Table 1. The 43 included studies were published between 1975 and 2016; 26 studies were prospective and 23 studies were published after the year 2000. A total of 3460 patients were evaluated, of which 1242 patients were diagnosed with CP [14-56]. The age of the patients ranged from 36 to 65 years, with a median of $50 \%$ male. Criteria for selection of patients were those with suspected pancreatic disease or patients with suspected CP. Patient characteristics are depicted in Table 2.

The risk of bias, assessed by QUADAS-2, was low in $28 \%$ of the studies and high in $19 \%$ of the studies. The concerns about applicability were low in $30 \%$ of the studies and high in $40 \%$ of the studies. The QUADAS- 2 characteristics for each domain are depicted in Fig. 2 and outlined for each study in Appendix Table 7. The quality of evidence for all five imaging modalities according to the GRADE scoring system was very
Table 3 Estimated overall sensitivity, specificity and heterogeneity according to imaging modality

\begin{tabular}{llclll}
\hline Modality & $N$ studies & $N$ patients & Sensitivity (95\% CI) & Specificity (95\% CI) & Heterogeneity $\left(I^{2}\right)$ \\
\hline EUS & 16 & 1249 & $81 \%(70-89 \%)$ & $90 \%(82-95 \%)$ & $82 \% / 73 \%$ \\
ERCP & 11 & 742 & $82 \%(76-87 \%)$ & $94 \%(87-98 \%)$ & $39 \% / 67 \%$ \\
MRCP & 14 & 933 & $78 \%(69-85 \%)$ & $96 \%(90-98 \%)$ & $59 \% / 65 \%$ \\
CT & 10 & 700 & $75 \%(66-83 \%)$ & $91 \%(81-96 \%)$ & $50 \% / 71 \%$ \\
US & 10 & 1005 & $67 \%(53-78 \%)$ & $98 \%(89-100 \%)$ & $40 \% / 93 \%$ \\
\hline
\end{tabular}

Random effects model 


\section{Forest plot: EUS}

Study
Albashir et al
Brand et al
Buscail et al
Catalano et al
Chong et al
Conwell et al
Giovannini et al
Glasbrenner et al
Lin et al
Nattermann et al
Pungpapong et al (1)
Pungpapong et al (2)
Stevens et al
Tox et al

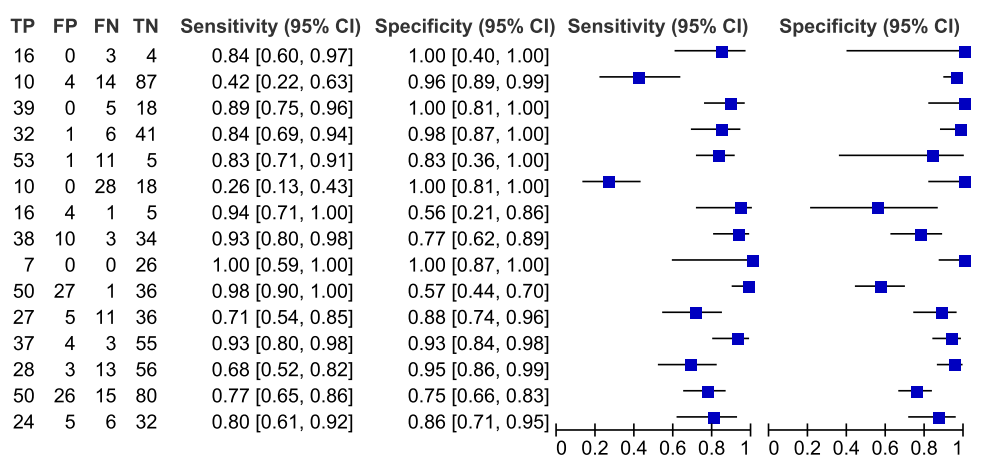

\section{Forest plot: ERCP}

$\begin{array}{lrrrrccc}\text { Study } & \text { TP } & \text { FP } & \text { FN } & \text { TN } & \text { Sensitivity }(95 \% \mathrm{CI}) & \text { Specificity }(95 \% \mathrm{Cl}) & \text { Sensitivity }(\mathbf{9 5 \%} \mathrm{CI}) \\ \text { Adamek et al } & 51 & 6 & 6 & 61 & 0.89[0.78,0.96] & 0.91[0.82,0.97] \\ \text { Buscail et al } & 33 & 0 & 11 & 18 & 0.75[0.60,0.87] & 1.00[0.81,1.00] \\ \text { Gebel et al } & 9 & 1 & 7 & 28 & 0.56[0.30,0.80] & 0.97[0.82,1.00] \\ \text { Glasbrenner et al } & 36 & 8 & 5 & 36 & 0.88[0.74,0.96] & 0.82[0.67,0.92] \\ \text { Gmelin et al } & 17 & 2 & 2 & 20 & 0.89[0.67,0.99] & 0.91[0.71,0.99] \\ \text { Lammer et al } & 33 & 2 & 6 & 66 & 0.85[0.69,0.94] & 0.97[0.90,1.00] \\ \text { Lawson et al } & 19 & 1 & 7 & 48 & 0.73[0.52,0.88] & 0.98[0.89,1.00] \\ \text { Parsi et al } & 17 & 1 & 7 & 10 & 0.71[0.49,0.87] & 0.91[0.59,1.00] \\ \text { Scarabino et al } & 10 & 17 & 2 & 34 & 0.83[0.52,0.98] & 0.67[0.52,0.79] \\ \text { Swobodnik et al } & 25 & 0 & 2 & 54 & 0.93[0.76,0.99] & 1.00[0.93,1.00] \\ \text { Triller et al } & 9 & 2 & 2 & 11 & 0.82[0.48,0.98] & 0.85[0.55,0.98]\end{array}$

\section{Forest plot: MRCP}

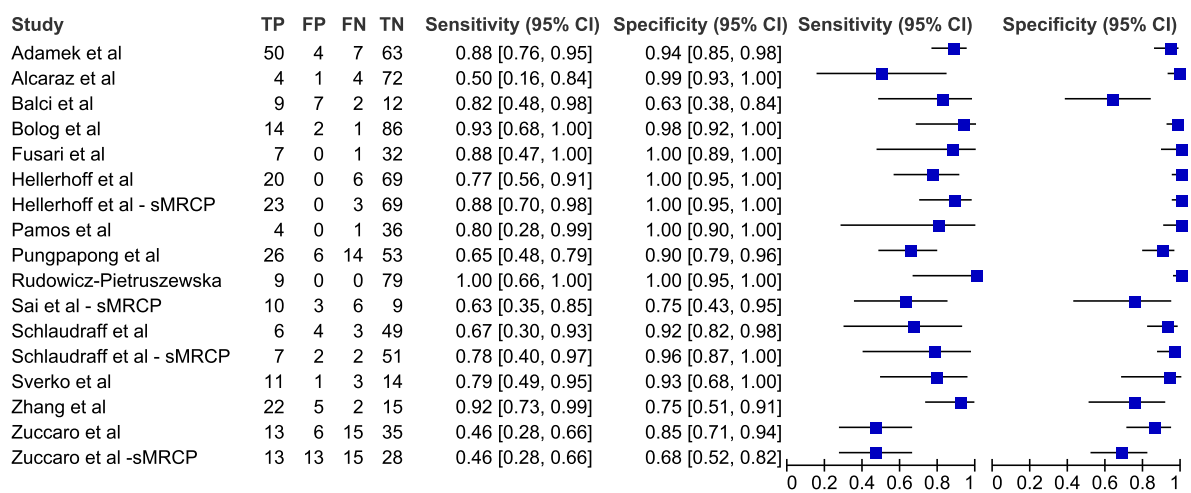

\section{Forest plot CT}

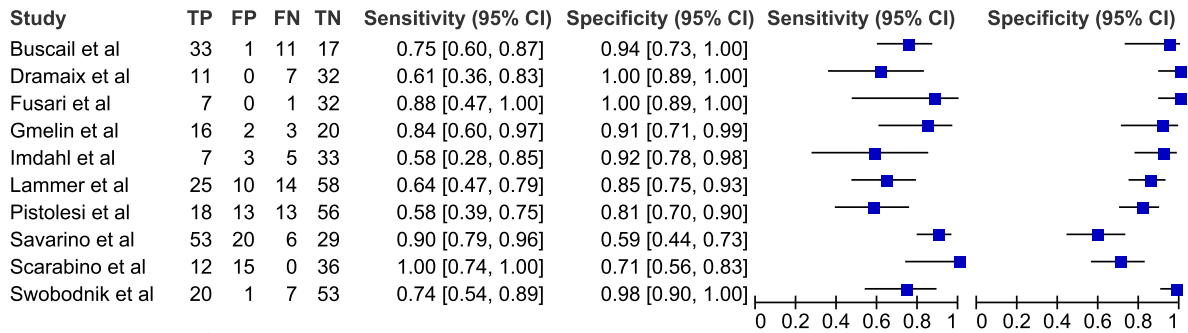

Forest plot: US

\begin{tabular}{|c|c|c|c|c|c|c|c|c|}
\hline Study & TP & FP & FN & TN & Sensitivity $(95 \% \mathrm{Cl})$ & Specificity $(95 \% \mathrm{Cl})$ & Sensitivity $(95 \% \mathrm{Cl})$ & Specificity $(95 \% \mathrm{Cl})$ \\
\hline Buscail et al & 26 & 4 & 18 & 14 & $0.59[0.43,0.74]$ & $0.78[0.52,0.94]$ & & \\
\hline Dramaix et al & 11 & 2 & 7 & 30 & $0.61[0.36,0.83]$ & $0.94[0.79,0.99]$ & & $\rightarrow$ \\
\hline Gebel et al & 18 & 1 & 4 & 33 & $0.82[0.60,0.95]$ & $0.97[0.85,1.00]$ & & $\rightarrow$ \\
\hline Gmelin et al & 13 & 0 & 6 & 22 & $0.68[0.43,0.87]$ & $1.00[0.85,1.00]$ & & $\longrightarrow$ \\
\hline Kremer et al & 42 & 5 & 21 & 378 & $0.67[0.54,0.78]$ & $0.99[0.97,1.00]$ & & - \\
\hline Lawson et al & 10 & 0 & 16 & 49 & $0.38[0.20,0.59]$ & $1.00[0.93,1.00]$ & & $\rightarrow$ \\
\hline Lees et al & 20 & 2 & 0 & 76 & $1.00[0.83,1.00]$ & $0.97[0.91,1.00]$ & . & $-\mathrm{m}$ \\
\hline Lin et al & 6 & 0 & 1 & 26 & $0.86[0.42,1.00]$ & $1.00[0.87,1.00]$ & $=$ & $\rightarrow$ \\
\hline Scarabino et al & 5 & 34 & 7 & 17 & $0.42[0.15,0.72]$ & $0.33[0.21,0.48]$ & & $\rightarrow-$ \\
\hline Swobodnik et al & 14 & 0 & 13 & 54 & $0.52[0.32,0.71]$ & $1.00[0.93,1.00]$ & 5 & $\rightarrow$ \\
\hline
\end{tabular}

Fig. 3 Forest plot for sensitivity and specificity 
low. The GRADE scores for each imaging modality and characteristics for each study are outlined in Appendix Tables 8 and 9.

EUS was the most frequently evaluated imaging modality; 16 studies including 1249 patients [15, 19-23, 27, 28, 36, 37, $41,42,48,51,53,56]$. ERCP was studied in 11 studies including 742 patients $[14,20,26,28,29,33,34,39,46,50$, 52]; MRCP, including secretin-enhanced MRCP, was evaluated in 14 studies including 933 patients [14, 16-18, 25, 30, 38, 42-44, 47, 49, 54, 55]; CT in 10 studies including 700 patients $[20,24,25,29,31,33,40,45,46,50]$ and abdominal US in 10 studies which included 1005 patients [20, 24, 26, 29, 32, 34-36, 46, 50]. The imaging characteristics for each study and modality in an individual study are listed in Appendix Table 11. Three of the 43 articles reported about complications of the imaging modality used; these were complications related to ERCP (being post-ERCP pancreatitis) with a mean complication rate of $4 \%[14,20,28]$.

\section{Overall diagnostic accuracy}

Analyses for summary estimates of sensitivity and specificity were done for EUS, ERCP, MRI, CT and US (Table 3). Figures 3 and 4 show sensitivity and specificity of individual studies in forest plots and in receiver operator curves (ROC), respectively. A negative covariance between the logit sensitivity and logit specificity was not obtained; therefore, no sROC for MRI and US could be drawn. The summary estimate of sensitivity for EUS, ERCP, MRCP, CT and US was $81 \%, 82 \%, 78 \%, 75 \%$ and $67 \%$, respectively. The summary estimate of specificity for EUS, ERCP, MRCP, CT and US was $90 \%, 94 \%, 96 \%, 91 \%$ and $98 \%$, respectively. Sensitivity of ERCP was significant higher than sensitivity of US ( $p=0.018)$. Other pairwise comparisons of sensitivity between imaging modalities revealed no significant difference. Specificity did not differ significantly among all modalities (Table 3). Sensitivity and specificity values for each study are listed in Appendix Table 10.

\section{Heterogeneity exploration}

The bivariate model for heterogeneity exploration showed that the factor 'flow and timing' was significantly associated with a higher sensitivity of US $(p=0.01)$. 'Description and verification with the reference standard' was significantly associated with a higher specificity for MRCP $(p=0.0002)$.

\section{Head to head comparison}

Six head to head comparisons were performed (Table 4). The specificity of ERCP and EUS, and the sensitivity of ERCP, EUS and CT in the summary estimates of the head to head studies were significantly higher as compared with US.
The head to head comparison of US versus ERCP comparison yields a sensitivity of 57\% (49-65\%) versus $78 \%$ (71$85 \%)(p<0.001)$; and a specificity of $94 \%(74-99 \%)$ versus

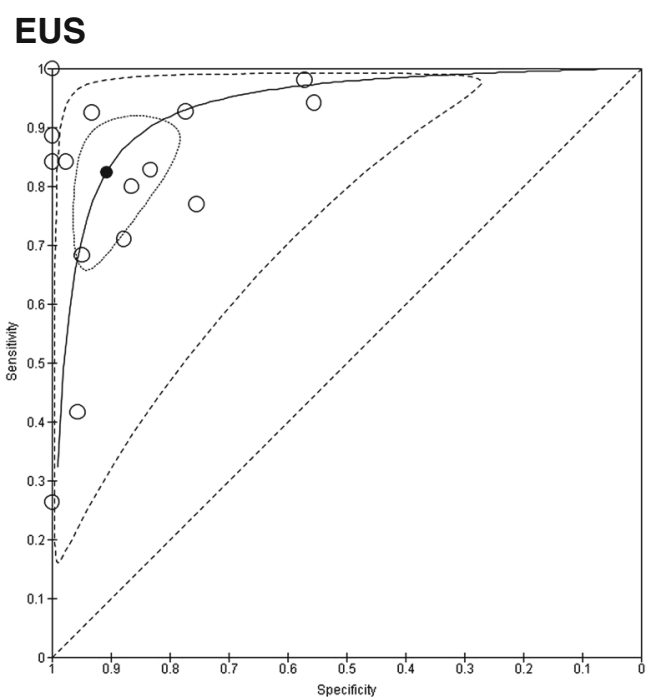

\section{ERCP}
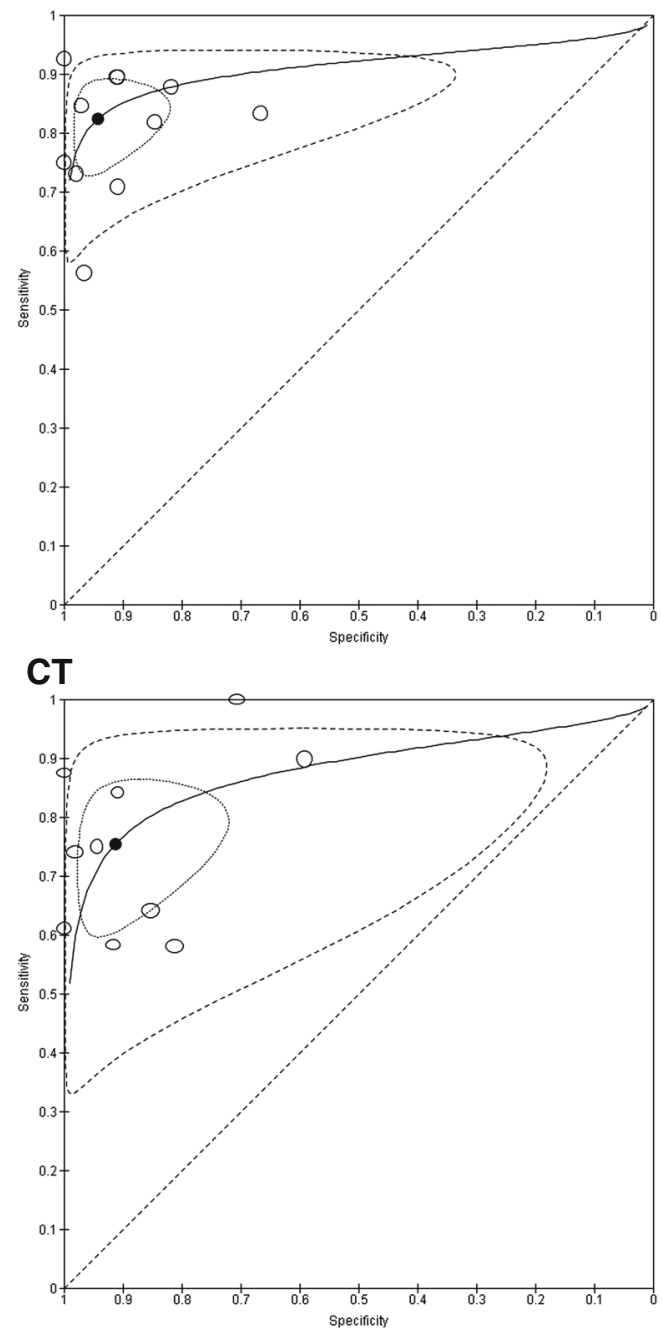

Fig. 4 Receiver operator curves (ROC) 
$98 \%(89-100 \%)(p=0.003)$, respectively [20, 26, 29, 34, 46, 50]. The comparison between US and CT yields a sensitivity of $58 \%(49-66 \%)$ and $77 \%(68-83 \%)(p=0.002)$, respectively [20, 24, 29, 46, 50]. And finally, the comparison of EUS versus US comparison yields a sensitivity of 90\% (82-98\%) versus $63 \%(49-76 \%)(p=0.001)$; and a specificity of $100 \%$ versus $91 \%(82-99 \%)(p=0.04)$, respectively [20, 36]. There were no significant differences in the sensitivity and specificity estimates between ERCP and EUS [20, 28, 53], MRCP and SMRCP [30, 47, 55] or ERCP and CT [20, 29, 33, 46, 50]. The heterogeneity $\left(I^{2}\right)$ between US and ERCP $(>25 \%)$ was higher $(>25 \%)$ than in the other comparisons $\left(I^{2} \leq 25 \%\right)$.

\section{Discussion}

EUS, ERCP, MRI and CT all have comparable high diagnostic accuracy in the initial diagnosis of chronic pancreatitis. EUS and ERCP are outperformers and US has the lowest accuracy. The choice of imaging modality can therefore be made on the basis of invasiveness, local availability, experience and costs.

Several recent guidelines [57-59] advocate the use of EUS, MRCP or CT for the diagnosis of CP, although summary estimates of their accuracy, thus far, were lacking. There is one guideline from Germany on $\mathrm{CP}$ that has reported sensitivity and specificity regarding EUS, ERCP, MRCP and US, although not for CT [60]. In this guideline 14 studies were selected, reporting ranges rather than pooling the data on sensitivity and specificity estimates. This method resulted in results slightly different from those in the present meta-analyses. For example the guideline reports a sensitivity of $70-80 \%$ for ERCP and $88 \%$ for MRI versus summary estimates of $82 \%$ and $78 \%$, respectively, in the present meta-analyses. The European Society of Radiology (ESR) is developing the ESR iGuide, a clinical decision support system for European imaging referral guidelines, covering various clinical scenarios, indications and recommendations (www.esriguide.org) [61-63]. The results from the present systematic review may be useful to incorporate in that system.

We excluded three studies where sensitivity and specificity data were provided, but it was not possible to extract sufficient data to produce $2 \times 2$ tables and calculate the diagnostic accuracy values, because only the sensitivity and specificity estimates were given [64-66]. In the study by Wang et al., estimates of sensitivity and specificity for EUS, ERCP and US were in line with the present results; the sensitivity of MR imaging and CT, however, were much lower (66\% and $61 \%$ ) [66]. The studies by Clave et al. and Orti et al. showed a lower sensitivity of ERCP (62\% and $70 \%$, respectively) compared to present results $(82 \%)[64,65]$.

The risk of missing important studies was minimized by performing a search in four major databases by two reviewers independently, without setting any restrictions for language and publication date. However, this systematic review has some limitations. The heterogeneity of the pooled studies was moderate to high in all analyses (between $39 \%$ and 93\%). However, in the head to head comparison analyses, the heterogeneity was low in most comparisons $(<25 \%)$. Furthermore, the heterogeneity of the reference standards used in the studies could have influenced individual study results. Surgery, histology and long-term follow-up of patients are reliable methods. Some reference standards, such as the use of endoscopic pancreatic function test (ePFT) for establishing the diagnosis of $\mathrm{CP}$, could have resulted in under- or
Table 4 Head to head comparison

\begin{tabular}{|c|c|c|c|c|c|}
\hline Comparison & $N$ studies & $N$ patients & Modality & Sensitivity (95\% CI) & Specificity $(95 \% \mathrm{CI})$ \\
\hline \multirow[t]{2}{*}{ US vs ERCP ${ }^{\mathrm{a}}$} & \multirow[t]{2}{*}{6} & \multirow[t]{2}{*}{423} & US & $57 \%(49-65 \%)$ & $94 \%(74-99 \%)$ \\
\hline & & & ERCP & $78 \%(71-85 \%)$ & $98 \%(89-100 \%)$ \\
\hline \multirow[t]{2}{*}{ US vs $\mathrm{CT}^{\mathrm{b}}$} & \multirow[t]{2}{*}{5} & \multirow[t]{2}{*}{297} & US & $58 \%(49-66 \%)$ & $77 \%(71-83 \%)$ \\
\hline & & & $\mathrm{CT}$ & $77 \%(68-83 \%)$ & $82 \%(74-88 \%)$ \\
\hline \multirow[t]{2}{*}{ CT vs ERCP ${ }^{b}$} & \multirow[t]{2}{*}{5} & \multirow[t]{2}{*}{354} & $\mathrm{CT}$ & $75 \%(67-82 \%)$ & $86 \%(81-90 \%)$ \\
\hline & & & ERCP & $84 \%(77-89 \%)$ & $90 \%(85-93 \%)$ \\
\hline \multirow[t]{2}{*}{ EUS vs ERCP ${ }^{b}$} & \multirow[t]{2}{*}{3} & \multirow[t]{2}{*}{214} & EUS & $88 \%(80-93 \%)$ & $85 \%(76-91 \%)$ \\
\hline & & & ERCP & $86 \%(78-91 \%)$ & $92 \%(85-96 \%)$ \\
\hline \multirow[t]{2}{*}{ MRCP vs sMRCP ${ }^{b}$} & \multirow[t]{2}{*}{3} & \multirow[t]{2}{*}{226} & MRCP & $62 \%(49-73 \%)$ & $94 \%(89-97 \%)$ \\
\hline & & & sMRCP & $68 \%(56-79 \%)$ & $91 \%(85-94 \%)$ \\
\hline \multirow[t]{2}{*}{ EUS vs US ${ }^{\mathrm{b}}$} & \multirow[t]{2}{*}{2} & \multirow[t]{2}{*}{95} & EUS & $90 \%(82-98 \%)$ & $100 \%$ \\
\hline & & & US & $63 \%(49-76 \%)$ & $91 \%(82-99 \%)$ \\
\hline
\end{tabular}

Sensitivity: US vs ERCP $(p<0.001)$, US vs CT $(p=0.002)$, EUS vs US $(p=0.001)$

Specificity: US vs ERCP $(p=0.003)$, EUS vs US $(p=0.04)$

${ }^{\text {a }}$ Random effects model

${ }^{\mathrm{b}}$ Fixed effects model 
overestimation of the sensitivity and specificity. In addition, the diagnosis of $\mathrm{CP}$ and the criteria used are different in different stages of the disease (e.g. absence of calcifications in the early phase of the disease). Another limitation was that our analyses included imaging studies and imaging protocols performed over the last 40 years in different centres with inherent variations in techniques and equipment. Especially in the last decade the quality of some imaging modalities (e.g. MRCP and $\mathrm{CT}$ ) has improved considerably. Also there were concerns about the quality of the available evidence, as assessed by QUADAS-2 and the GRADE scoring system.

The highest scores for accuracy in the diagnosis of CP were found for EUS and ERCP, but these are invasive techniques. ERCP has a relatively high risk of complications, such as postERCP pancreatitis (1.6-15.7\%, mean complication rate of $4 \%$ ) and is nowadays only used for therapeutic purposes (e.g. stenting of pancreatic duct) [67-69]. To date, diagnostic ERCP is largely replaced by EUS and the cross-sectional imaging modalities $\mathrm{CT}$ and MRCP.

It has been suggested that $\mathrm{CT}$ is better in detecting parenchymal calcifications and intraductal calcifications compared to MRCP [70-73]. On the other hand, MRCP is more often able to detect significant abnormalities of the pancreatic duct (e.g. PD dilatation and strictures) and slight changes of the pancreatic parenchyma and side branches, which can be attributed to early signs CP (i.e. atrophy, side branch ectasia) compared to CT [74]. Early diagnosis can also lead to a timely start of treatment, which has been associated with improved long-term outcome [75]. Nevertheless, for very early CP this association needs to be established in further research, such as the ESCAPE trial, evaluating the effect of early intervention in patients with CP [76]. As diagnostic sensitivity of CT and MRCP is not significantly lower than that of ERCP and EUS, and specificity is comparable, non-invasive modalities except for US are a likely first choice in patients with suspected pancreatic disease including chronic pancreatitis.

\begin{abstract}
Acknowledgements The scientific guarantor of this publication is M.A. Boermeester. The authors of this manuscript declare relationships with the following companies: Baxter, Acelity/KCI, Ipsen, Mylan, Johnson \& Johnson, Bard. The authors of this manuscript declare no relationships with any companies whose products or services may be related to the subject matter of the article. The authors state that this work has not received any funding. Two of the authors have significant statistical expertise (SB, MAB). Institutional review board approval was not required because of the nature of the study (a systematic review).
\end{abstract}

\section{APPENDIX}

Table 5 Search terms

\begin{tabular}{lll}
\hline & MeSH terms & All Fields \\
\hline $\begin{array}{l}\text { Chronic } \\
\text { pancreatitis }\end{array}$ & Pancreatitis, chronic [MeSH] & Chronic pancreatitis [All Fields] \\
AND & & \\
EUS & & EUS [All Fields] \\
ERCP & Endosonography [MeSH] & \\
OR & Cholangiopancreatography, Endoscopic & Endoscopic Retrograde Cholangiopancreatograp* \\
MRCP & Retrograde [MeSH] & [All Fields] OR ERCP [All Fields] \\
& Magnetic Resonance Imaging [MeSH] & Magnetic resonance imaging [All Fields] \\
& OR & OR MRI [All Fields] OR MRCP [All Fields] \\
OR & Cholangiopancreatography, Magnetic & OR Magnetic Resonance Cholangio* [All \\
SMRCP & Resonance [MeSH] & Fields] \\
OR & & Magnetic Resonance Imaging [All Fields] \\
CT & & AND secretin [All Fields] OR sMRI [All Fields] \\
& & \\
& Tomography, X-Ray Computed [MeSH] & (Tomography [All Fields] AND x-ray \\
OR & & [All Fields] AND computed [All Fields]) \\
US & OR Computed Tomography [All Fields]) \\
& OR CT scan* [All Fields] \\
\hline
\end{tabular}

MeSH Medical Subject Headings 
Table 6 Excluded articles based on full text

\begin{tabular}{|c|c|c|c|}
\hline Author & Year & Journal & Reason for exclusion \\
\hline Borsukov et al & 2001 & Ross Gastroenterol Zh & Article not available \\
\hline Diad'kin et al & 2013 & Vestnik rentgenologii i radiologii & Article not available \\
\hline Dotsenko et al & 1985 & Vrach Delo & Article not available \\
\hline Rosch et al & 1989 & Z Gastroenterologie & Article not available \\
\hline Suzdalev et al & 1992 & Likars'ka sprava & Article not available \\
\hline Agarwal et al & 2008 & GIE & Exclusive patient group \\
\hline Brailski et al & 1989 & Vutr Boles & Exclusive patient group \\
\hline Brailski et al & 1984 & Vutr Boles & Exclusive patient group \\
\hline Brimiene et al & 2011 & Medicina & Exclusive patient group \\
\hline Carlucci et al & 1989 & HPB Surgery & Exclusive patient group \\
\hline Chowdhury et al & 2005 & Pancreas & Exclusive patient group \\
\hline Cotton et al & 1980 & Radiology & Exclusive patient group \\
\hline DelMaschio et al & 1991 & Radiology & Exclusive patient group \\
\hline Erturk et al & 2006 & Am J Gastroenterol & Exclusive patient group \\
\hline Frick et al & 1982 & Gastrointest Rad & Exclusive patient group \\
\hline Gheonea et al & 2013 & BMC Gastroenterology & Exclusive patient group \\
\hline Goodale et al & 1981 & Ann Surg & Exclusive patient group \\
\hline Hanninen et al & 2002 & Radiology & Exclusive patient group \\
\hline Hatano et al & 1998 & Nippon rinsho J & Exclusive patient group \\
\hline Hocke et al & 2008 & Dtsch Med Wochenschr & Exclusive patient group \\
\hline Hocke et al & 2006 & WJG & Exclusive patient group \\
\hline Hocke et al & 2012 & Z Gastroenterologie & Exclusive patient group \\
\hline Huang et al & 2011 & J Dig dis & Exclusive patient group \\
\hline Imbriaco et al & 2006 & Radiol Med & Exclusive patient group \\
\hline Kawai et al & 2012 & Eur J Rad & Exclusive patient group \\
\hline Kim et al & 2007 & J MRI & Exclusive patient group \\
\hline Kursawa et al & 1991 & Radiol Diagn & Exclusive patient group \\
\hline Lu et al & 2013 & Acad J Sec Mil Med University & Exclusive patient group \\
\hline Lutz et al & 1975 & Klin Wschr & Exclusive patient group \\
\hline Morris-Stiff et al & 2009 & J Pancreas & Exclusive patient group \\
\hline Papp et al & 1978 & Wiener klin Wchnschrft & Exclusive patient group \\
\hline Pomerri et al & 1991 & Radiologia Med & Exclusive patient group \\
\hline Rosch et al & 2000 & Am J Gastroenterol & Exclusive patient group \\
\hline Sandrasegaran et al & 2013 & AJR & Exclusive patient group \\
\hline Sendler et al & 2000 & World J Surg & Exclusive patient group \\
\hline Sugumar et al & 2011 & Gut & Exclusive patient group \\
\hline Testoni et al & 1981 & Acta Endoscopica & Exclusive patient group \\
\hline Tiushin et al & 2003 & Voprosy onkologii & Exclusive patient group \\
\hline Varadarajulu et al & 2007 & GIE & Exclusive patient group \\
\hline Viceconte et al & 1980 & Ann ital chir & Exclusive patient group \\
\hline Yamada et al & 2010 & Abdom Imaging & Exclusive patient group \\
\hline Zhu et al & 2013 & PLOS one & Exclusive patient group \\
\hline Bhutani et al & 2009 & Pancreas & In vitro \\
\hline Akisik et al & 2013 & AJR & No diagnostic values for $\mathrm{CP}$ \\
\hline Alempijević et al & 2005 & Vojnosanit Pregl & No diagnostic values for $\mathrm{CP}$ \\
\hline Alpern et al & 1985 & Radiology & No diagnostic values for $\mathrm{CP}$ \\
\hline Ardelean et al & 2014 & Med Ultrason & No diagnostic values for $\mathrm{CP}$ \\
\hline Ardengh et al & 2011 & GIE & No diagnostic values for $\mathrm{CP}$ \\
\hline Ascunce et al & 2010 & Surg End & No diagnostic values for $\mathrm{CP}$ \\
\hline Baert et al & 1977 & Radiologe & No diagnostic values for $\mathrm{CP}$ \\
\hline Balci et al & 2010 & $\mathrm{~J}$ MRI & No diagnostic values for $\mathrm{CP}$ \\
\hline Beliao et al & 2012 & Eur J Rad & No diagnostic values for $\mathrm{CP}$ \\
\hline Bender et al & 1999 & Invest Rad & No diagnostic values for $\mathrm{CP}$ \\
\hline Bhatt et al & 2005 & Indian J Rad Imag Ass & No diagnostic values for $\mathrm{CP}$ \\
\hline Bonanno et al & 1994 & Giorn Ital End Dig & No diagnostic values for $\mathrm{CP}$ \\
\hline Bruhlmann et al & 1976 & RoFo & No diagnostic values for $\mathrm{CP}$ \\
\hline Caletti et al & 1982 & British j Surgery & No diagnostic values for $\mathrm{CP}$ \\
\hline $\mathrm{Cao}$ & 1989 & Zhonghua yi xue za zhi & No diagnostic values for $\mathrm{CP}$ \\
\hline Cappeliez et al & 2000 & Radiology & No diagnostic values for $\mathrm{CP}$ \\
\hline Chang et al & 2010 & GIE & No diagnostic values for $\mathrm{CP}$ \\
\hline
\end{tabular}


Table 6 (continued)

\begin{tabular}{|c|c|c|c|}
\hline Author & Year & Journal & Reason for exclusion \\
\hline Cohen et al & 2014 & Dig Dis Sci & No diagnostic values for $\mathrm{CP}$ \\
\hline Concia et al & 2014 & Invest Rad & No diagnostic values for $\mathrm{CP}$ \\
\hline Dale et al & 1979 & Electromedica & No diagnostic values for $\mathrm{CP}$ \\
\hline Das et al & 2008 & GIE & No diagnostic values for $\mathrm{CP}$ \\
\hline Delbeke et al & 1999 & J Nucl Med & No diagnostic values for $\mathrm{CP}$ \\
\hline Dite et al & 1982 & Vnitrni Lekarstvi & No diagnostic values for $\mathrm{CP}$ \\
\hline Dronamraju et al & 2016 & Ann Gastroenterol & No diagnostic values for $\mathrm{CP}$ \\
\hline D'Souza et al & 2015 & Dig Dis Sci & No diagnostic values for $\mathrm{CP}$ \\
\hline Eitner et al & 1979 & $\begin{array}{l}\text { Dtsch Zeitschr Verdauungs- und } \\
\text { Stoffwechselkrankheiten }\end{array}$ & No diagnostic values for $\mathrm{CP}$ \\
\hline Eloubeidi et al & 2013 & Pancreas & No diagnostic values for $\mathrm{CP}$ \\
\hline Ergul et al & 2014 & Rev Esp Med Nucl Im Mol & No diagnostic values for $\mathrm{CP}$ \\
\hline Ferrucci et al & 1979 & Radiology & No diagnostic values for $\mathrm{CP}$ \\
\hline Foley et al & 1980 & Gastrointest Rad & No diagnostic values for $\mathrm{CP}$ \\
\hline Fontana et al & 1976 & Gut & No diagnostic values for $\mathrm{CP}$ \\
\hline Foster et al & 1984 & BMJ & No diagnostic values for $\mathrm{CP}$ \\
\hline Gardner et al & 2014 & Pancreas & No diagnostic values for $\mathrm{CP}$ \\
\hline Gincul et al & 2014 & Endoscopy & No diagnostic values for $\mathrm{CP}$ \\
\hline Gowland et al & 1981 & Lancet & No diagnostic values for $\mathrm{CP}$ \\
\hline Grant et al & 1981 & $\mathrm{~J}$ Am Osteopathic Ass & No diagnostic values for $\mathrm{CP}$ \\
\hline Harada et al & 1977 & Gastroenterologica Jap & No diagnostic values for $\mathrm{CP}$ \\
\hline He et al & 2014 & Pancreas & No diagnostic values for $\mathrm{CP}$ \\
\hline Hoki et al & 2009 & J Gastroenterol & No diagnostic values for $\mathrm{CP}$ \\
\hline Hollerbach et al & 1994 & Med Klinik & No diagnostic values for $\mathrm{CP}$ \\
\hline Horii et al & 1982 & Jap J Gastroenterol & No diagnostic values for $\mathrm{CP}$ \\
\hline Johnson et al & 1999 & Radiology & No diagnostic values for $\mathrm{CP}$ \\
\hline Jones et al & 1988 & Clin Radiol & No diagnostic values for $\mathrm{CP}$ \\
\hline Kamisawa et al & 2007 & J Gastroenterol & No diagnostic values for $\mathrm{CP}$ \\
\hline Kersting et al & 2009 & Gastroenterology & No diagnostic values for $\mathrm{CP}$ \\
\hline Kitano et al & 2004 & Gut & No diagnostic values for $\mathrm{CP}$ \\
\hline Laghi et al & 1998 & Chirurgia & No diagnostic values for $\mathrm{CP}$ \\
\hline Leblanc et al & 2014 & Pancreas & No diagnostic values for $\mathrm{CP}$ \\
\hline Leblanc et al & 2014 & Pancreas & No diagnostic values for $\mathrm{CP}$ \\
\hline Li et al & 2001 & Zhongguo yi xue ke xue & No diagnostic values for $\mathrm{CP}$ \\
\hline Loginov et al & 1976 & Sovetskaya Meditsina & No diagnostic values for $\mathrm{CP}$ \\
\hline Lopez et al & 2002 & Radiology & No diagnostic values for $\mathrm{CP}$ \\
\hline Manfredi & 2000 & Radiology & No diagnostic values for $\mathrm{CP}$ \\
\hline Modder et al & 1979 & RoFo & No diagnostic values for $\mathrm{CP}$ \\
\hline Montori et al & 1979 & Min Diet Gastroent & No diagnostic values for $\mathrm{CP}$ \\
\hline Napoleon et al & 2010 & Endoscopy & No diagnostic values for $\mathrm{CP}$ \\
\hline Novis et al & 1976 & S Afr Med J & No diagnostic values for $\mathrm{CP}$ \\
\hline Ohtsubo et al & 2008 & Gastroenterolog Endoscopy & No diagnostic values for $\mathrm{CP}$ \\
\hline Orlikov et al & 2007 & Ter Arkh & No diagnostic values for $\mathrm{CP}$ \\
\hline Park et al & 2008 & The Korean J Gastroenter & No diagnostic values for $\mathrm{CP}$ \\
\hline Petersein et al & 2002 & RoFo & No diagnostic values for $\mathrm{CP}$ \\
\hline Pezzelli et al & 2013 & Pancreas & No diagnostic values for $\mathrm{CP}$ \\
\hline Pomerri et al & 1987 & Radiologia Med & No diagnostic values for $\mathrm{CP}$ \\
\hline Rickes et al & 2002 & Scand J Gastroenterol & No diagnostic values for $\mathrm{CP}$ \\
\hline Rosenberger et al & 1979 & MMW & No diagnostic values for $\mathrm{CP}$ \\
\hline Russell et al & 1978 & Gut & No diagnostic values for $\mathrm{CP}$ \\
\hline Sahai et al & 1998 & GIE & No diagnostic values for $\mathrm{CP}$ \\
\hline Sainani et al & 2009 & AJG & No diagnostic values for $\mathrm{CP}$ \\
\hline Sica et al & 2002 & J MRI & No diagnostic values for $\mathrm{CP}$ \\
\hline Sica et al & 1999 & Radiology & No diagnostic values for $\mathrm{CP}$ \\
\hline Songur et al & 2000 & Digest Endoscopy & No diagnostic values for $\mathrm{CP}$ \\
\hline Stevens et al & 2010 & WJG & No diagnostic values for $\mathrm{CP}$ \\
\hline Struve et al & 1982 & Diagnostik \& Intensivtherapie & No diagnostic values for $\mathrm{CP}$ \\
\hline Sun et al & 2010 & Acad J Sec Mil Med University & No diagnostic values for $\mathrm{CP}$ \\
\hline Tamura et al & 2006 & Radiology & No diagnostic values for $\mathrm{CP}$ \\
\hline Tellez-Avila et al & 2014 & WJG & No diagnostic values for $\mathrm{CP}$ \\
\hline
\end{tabular}


Table 6 (continued)

\begin{tabular}{|c|c|c|c|}
\hline Author & Year & Journal & Reason for exclusion \\
\hline Tirkes et al & 2016 & J MRI & No diagnostic values for $\mathrm{CP}$ \\
\hline Trikudanathan et al & 2015 & Am J Gastroenterol & No diagnostic values for $\mathrm{CP}$ \\
\hline Tripathi et al & 2002 & Indian J Gastroenterol & No diagnostic values for $\mathrm{CP}$ \\
\hline Tympner et al & 1979 & Leber Magen Darm & No diagnostic values for $\mathrm{CP}$ \\
\hline Tympner et al & 1977 & $\begin{array}{l}\text { Verhand Dtschen Gesellschaft fur Innere } \\
\text { Medizin }\end{array}$ & No diagnostic values for $\mathrm{CP}$ \\
\hline Uskudar et al & 2009 & Pancreas & No diagnostic values for $\mathrm{CP}$ \\
\hline Valentini et al & 1981 & Endoscopy & No diagnostic values for $\mathrm{CP}$ \\
\hline Varghese et al & 2002 & Clin Radiol & No diagnostic values for $\mathrm{CP}$ \\
\hline Wang et al & 2013 & WJG & No diagnostic values for $\mathrm{CP}$ \\
\hline $\begin{array}{l}\text { Wierzbicka-Paczos } \\
\text { et al }\end{array}$ & 1998 & Gastroenterologia Polska & No diagnostic values for $\mathrm{CP}$ \\
\hline $\begin{array}{l}\text { Wierzbicka-Paczos } \\
\text { et al }\end{array}$ & 1999 & Polski Merk Lek & No diagnostic values for $\mathrm{CP}$ \\
\hline Will et al & 2010 & Ultraschall Med & No diagnostic values for $\mathrm{CP}$ \\
\hline Zaheer et al & 2014 & Eur J Rad & No diagnostic values for $\mathrm{CP}$ \\
\hline Bian et al & 2014 & Chin J Radiol & No reference standard \\
\hline Braganza et al & 1978 & Clin Radiol & No reference standard \\
\hline Gillams et al & 2007 & Eur J Rad & No reference standard \\
\hline Helmberger et al & 2000 & RoFo & No reference standard \\
\hline $\begin{array}{l}\text { Hernandez Garces } \\
\text { et al }\end{array}$ & 2004 & J Pancreas & No reference standard \\
\hline Ho et al & 2006 & Clin Gastroenterol Hep & No reference standard \\
\hline Kalmar et al & 1984 & Southern Medical J & No reference standard \\
\hline Kalmin et al & 2011 & Can J Gastroenterol & No reference standard \\
\hline Kaufman et al & 1989 & GIE & No reference standard \\
\hline Kumon et al & 2012 & GIE & No reference standard \\
\hline Manfredi et al & 1998 & La Rad Medica & No reference standard \\
\hline Novotny et al & 2000 & Bratisl Lek Listy & No reference standard \\
\hline Ponette et al & 1976 & Acta Gastro-Enterol Belgica & No reference standard \\
\hline Sanyal et al & 2012 & AJR & No reference standard \\
\hline Yoshimoto et al & 1980 & Jap J Gastroenterol & No reference standard \\
\hline Grossjohann et al & 2010 & Scand J Gastroenterol & Not enough patients \\
\hline Sood et al & 1992 & Indian J Gastroenterol & Not enough patients \\
\hline Zhi et al & 2002 & Chin J Digestive Dis & Not enough patients \\
\hline Zhong et al & 2003 & WJG & Not enough patients \\
\hline Ainsworth et al & 2003 & Endoscopy & Only sensitivity reported \\
\hline Bastid et al & 1995 & $\mathrm{~J}$ d'Echographie et de Med par Ultrasons & Only sensitivity reported \\
\hline Campisi et al & 2009 & Clin Radiol & Only sensitivity reported \\
\hline Dancygier et al & 1986 & Scand J Gastroenterol & Only sensitivity reported \\
\hline Giday et al & 2011 & J Gastr Hep & Only sensitivity reported \\
\hline Guarita et al & 1982 & $\mathrm{AMB}$ & Only sensitivity reported \\
\hline Guo et al & 2003 & Chin J Digestive Dis & Only sensitivity reported \\
\hline Kahl et al & 2002 & GIE & Only sensitivity reported \\
\hline Kim et al & 2001 & AJR & Only sensitivity reported \\
\hline Kolmannskog et al & 1981 & Acta Radiologica & Only sensitivity reported \\
\hline Lackner et al & 1980 & RoFo & Only sensitivity reported \\
\hline Lawson & 1978 & Radiology & Only sensitivity reported \\
\hline Manfredi & 2002 & Radiology & Only sensitivity reported \\
\hline Mao et al & 2011 & WCJD & Only sensitivity reported \\
\hline Nakashio & 1992 & Acta medica & Only sensitivity reported \\
\hline Noguchi et al & 1985 & Gastroenterolog Endoscopy & Only sensitivity reported \\
\hline Propp & 2011 & Vestnik khirurgii imeni & Only sensitivity reported \\
\hline Rossi et al & 1996 & Giorn Ital End Dig & Only sensitivity reported \\
\hline Sahel et al & 1976 & Acta Endoscopica & Only sensitivity reported \\
\hline Seicean et al & 2010 & Ultraschall Med & Only sensitivity reported \\
\hline Sildiroglu & 1985 & Rontgenpraxis & Only sensitivity reported \\
\hline Singh et al & 1993 & Indian J Rad Imag & Only sensitivity reported \\
\hline Sivak et al & 1986 & Scand J Gastroenterol & Only sensitivity reported \\
\hline Stabile Ianora et al & 2013 & Recenti Prog Med & Only sensitivity reported \\
\hline Stevens et al & 2008 & Dig Dis Sci & Only sensitivity reported \\
\hline
\end{tabular}


Table 6 (continued)

\begin{tabular}{|c|c|c|c|}
\hline Author & Year & Journal & Reason for exclusion \\
\hline Stevens et al & 2010 & Dig Dis Sci & Only sensitivity reported \\
\hline Triller et al & 1983 & Computertomographie & Only sensitivity reported \\
\hline Uchida et al & 1997 & Jap J Clin Radiology & Only sensitivity reported \\
\hline Vitale et al & 2009 & The Am Surgeon & Only sensitivity reported \\
\hline Wang et al & 2009 & J Gastr Hep & Only sensitivity reported \\
\hline Wu et al & 2006 & World Chin J Dig & Only sensitivity reported \\
\hline Yanling et al & 2001 & Chinese J Gastroenterol & Only sensitivity reported \\
\hline Zhou et al & 1993 & Zhonghua nei ke za zhi & Only sensitivity reported \\
\hline Aithal et al & 2002 & GIE & Other disease \\
\hline Doust et al & 1976 & Radiology & Other disease \\
\hline Engjom et al & 2015 & Scan J Gastroenterol & Other disease \\
\hline Huang et al & 2009 & Acad J Sec Mil Med University & Other disease \\
\hline Kushnir et al & 2011 & GIE & Other disease \\
\hline Lai et al & 2004 & Endoscopy & Other disease \\
\hline Leblanc et al & 2014 & Pancreas & Other disease \\
\hline Matos et al & 2001 & GIE & Other disease \\
\hline Mosler et al & 2012 & Dig Dis Sci & Other disease \\
\hline Novis et al & 2010 & Rev Colegio Brasileiro Cirurg & Other disease \\
\hline Rana et al & 2012 & J Gastr Hep & Other disease \\
\hline Ranney et al & 2012 & GIE & Other disease \\
\hline Sainani et al & 2015 & Pancreas & Other disease \\
\hline Soto et al & 2005 & Radiology & Other disease \\
\hline Akisik et al & 2009 & Radiology & Other imaging modality \\
\hline Cherian et al & 2010 & HPB Surgery & Other imaging modality \\
\hline Glaser et al & 1994 & Int J Pancreatology & Other imaging modality \\
\hline Glaser et al & 1989 & Scand J Gastroenterol & Other imaging modality \\
\hline Glaser et al & 1985 & Ultraschall Med & Other imaging modality \\
\hline Hocke et al & 2007 & Pancreas & Other imaging modality \\
\hline Kumon et al & 2010 & GIE & Other imaging modality \\
\hline Saftoiu et al & 2008 & GIE & Other imaging modality \\
\hline Sreenarasimhaiah & 2008 & $\mathrm{~J}$ Clin Gastroenterol & Other imaging modality \\
\hline Tummula et al & 2013 & Clin Transl Gastroenterol & Other imaging modality \\
\hline Uehara et al & 2011 & J Gastr Hep & Other imaging modality \\
\hline Abdalla et al & 2012 & Gastroenterolgy & Other type of article \\
\hline Arsac et al & 1981 & Med Chirurgie Digest & Other type of article \\
\hline Ashida et al & 2011 & J Gastr Hep & Other type of article \\
\hline Chvatalova et al & 2012 & Pancreatology & Other type of article \\
\hline Czako et al & 2007 & J Gastroenterol & Other type of article \\
\hline Gupta et al & 2013 & JIMSA & Other type of article \\
\hline Heverhagen et al & 2007 & RoFo & Other type of article \\
\hline Kasugai et al & 1982 & Stomach and intestine & Other type of article \\
\hline Kent et al & 2008 & Pancreas & Other type of article \\
\hline Markwardt et al & 1980 & Radiologia Diagn & Other type of article \\
\hline Munoz et al & 2010 & Rev Med de Chile & Other type of article \\
\hline Musunuri et al & 2015 & Ind J Gastroenterol & Other type of article \\
\hline Quinn et al & 2012 & Gut & Other type of article \\
\hline Romagnuolo et al & 2012 & GIE & Other type of article \\
\hline Sherman et al & 2012 & GIE & Other type of article \\
\hline Shibukawa et al & 2015 & Dig Endos & Other type of article \\
\hline Stevens et al & 2008 & Pancreas & Other type of article \\
\hline Takahashi et al & 2014 & AJR & Other type of article \\
\hline Trus et al & 1998 & Probl Gen Surg & Other type of article \\
\hline Vadrot et al & 1981 & Med Chirurgie Digest & Other type of article \\
\hline Zaruba et al & 2012 & Pancreatology & Other type of article \\
\hline Zhang et al & 2011 & J Gastr Hep & Other type of article \\
\hline
\end{tabular}


Table 7 QUADAS-2 characteristics for each study

\begin{tabular}{|c|c|c|c|c|c|c|c|}
\hline \multirow[t]{2}{*}{ Study } & \multicolumn{4}{|l|}{ Bias } & \multicolumn{3}{|l|}{ Applicability } \\
\hline & Patient selection & Index test & Reference standard & Flow and timing & Patient selection & Index test & Reference standard \\
\hline Adamek et al & Low & Low & Low & Low & Unclear & Unclear & Low \\
\hline Albashir et al & Low & Low & Low & Low & Low & Low & Low \\
\hline Alcaraz et al & Low & Low & Low & Low & High & Unclear & Low \\
\hline Balci et al & Low & Low & Unclear & Low & Low & Low & Unclear \\
\hline Bolog et al & Low & Unclear & Low & Low & High & Unclear & Low \\
\hline Brand et al & Low & Low & Low & High & High & Low & Low \\
\hline Buscail et al & Low & Unclear & Low & Low & High & Unclear & Low \\
\hline Catalano et al & Unclear & Low & Unclear & Low & Low & Low & Low \\
\hline Chong et al & Low & Low & Low & Low & Low & Low & Low \\
\hline Conwell et al & Low & Low & High & Low & Low & Low & Unclear \\
\hline Dramaix et al & Low & Low & Low & Low & Low & Unclear & Low \\
\hline Fusari et al & Unclear & Low & Low & Low & High & Low & Low \\
\hline Gebel et al & Low & Low & Low & High & Low & Unclear & Low \\
\hline Giovannini et al & Unclear & Unclear & Low & Low & High & Unclear & Unclear \\
\hline Glasbrenner et al & Low & Low & Low & Low & High & Low & Low \\
\hline Gmelin et al & Low & Low & Low & Low & Low & High & Unclear \\
\hline Hellerhoff et al & Low & Low & Low & Low & Low & Low & Low \\
\hline Imdahl et al & Low & Low & Unclear & Low & Low & Unclear & Low \\
\hline Kremer et al & High & Unclear & Unclear & High & High & Unclear & Low \\
\hline Lammer et al & Low & Low & Unclear & Low & Low & Unclear & Unclear \\
\hline Lawson et al & Low & Low & Unclear & Low & Low & Low & Unclear \\
\hline Lees et al & Low & Low & Low & High & Low & High & Low \\
\hline Lin et al & High & Unclear & Low & Low & Low & Unclear & Low \\
\hline Nattermann et al & Unclear & Low & Low & Low & High & Unclear & Low \\
\hline Pamos et al & Low & Low & Low & Low & High & Unclear & Low \\
\hline Parsi et al & Low & Low & Low & Low & Low & Low & Low \\
\hline Pistolesi et al & Unclear & Low & Low & Low & Low & Low & Low \\
\hline Pungpapong et al & Low & Low & Low & Low & Low & Low & Low \\
\hline Pungpapong et al & Low & Unclear & Unclear & Low & Low & Low & Low \\
\hline Rudowicz Pietr-uszewska et al & Low & Unclear & Low & Low & High & Unclear & Unclear \\
\hline Sai et al & High & Low & Low & Low & Low & Low & Low \\
\hline Savarino et al & Unclear & Low & Low & Low & Low & Low & Low \\
\hline Scarabino et al & Low & Unclear & Unclear & Low & High & Unclear & Unclear \\
\hline Schlaudraff et al & Low & Unclear & Low & Low & Low & Low & Low \\
\hline Stevens et al & Low & Low & Unclear & Low & Low & Low & Unclear \\
\hline Sverko et al & Unclear & Unclear & Low & Low & Low & Unclear & Low \\
\hline Swobodnik et al & Low & Low & Low & Low & Low & Low & Low \\
\hline Tox et al & Low & Unclear & Unclear & Low & Low & Low & Low \\
\hline Trikudanathan et al & Unclear & Low & Unclear & Low & High & Low & Low \\
\hline Triller et al & Unclear & Low & Unclear & Low & Unclear & Unclear & Low \\
\hline Wiersema et al & Unclear & Low & Unclear & Low & High & Low & Unclear \\
\hline Zhang et al & High & Unclear & High & Low & Low & Unclear & High \\
\hline Zuccaro et al & Unclear & Low & Unclear & Low & Low & Low & Unclear \\
\hline
\end{tabular}




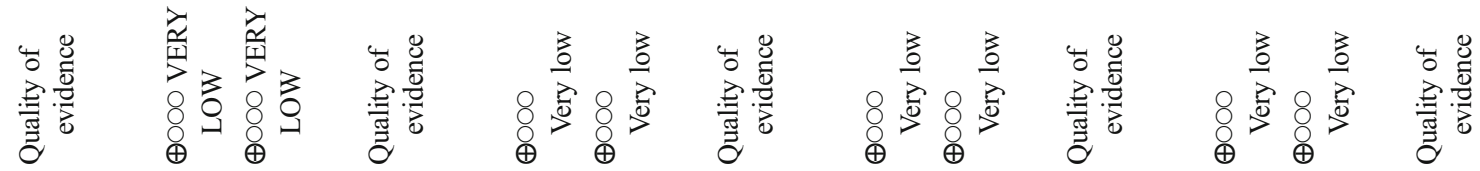

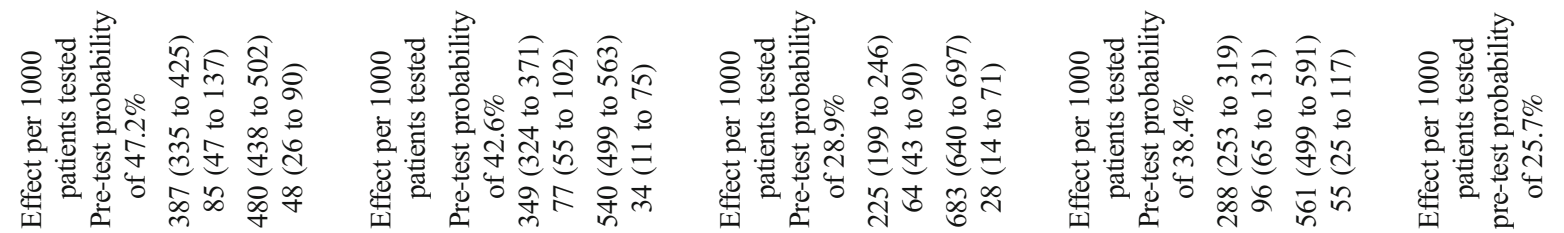

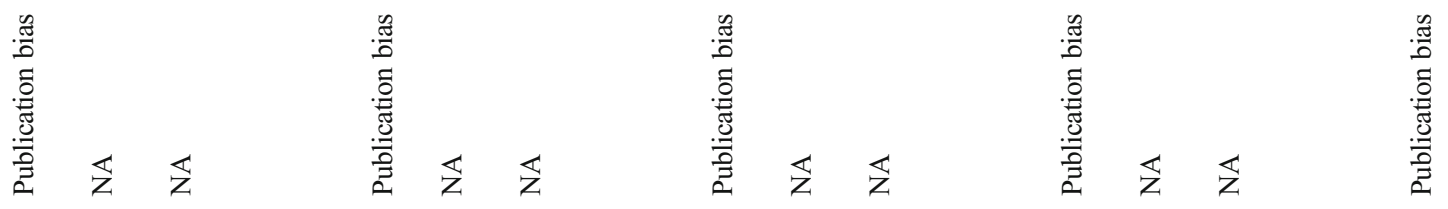

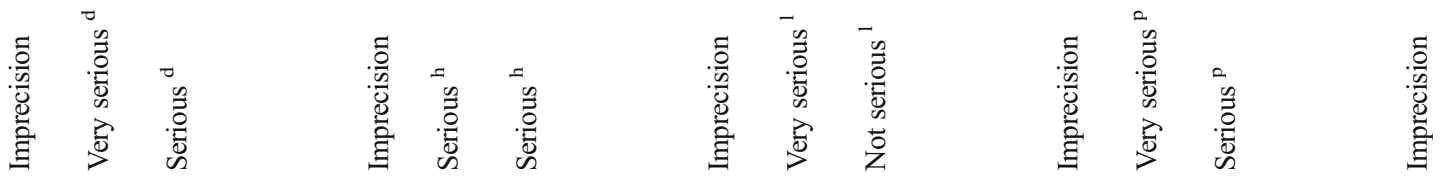

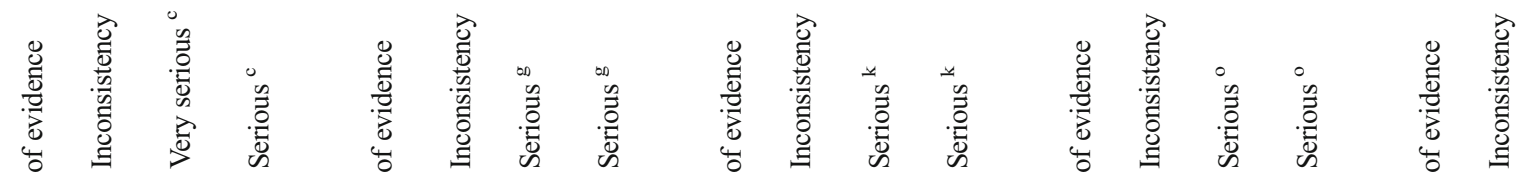

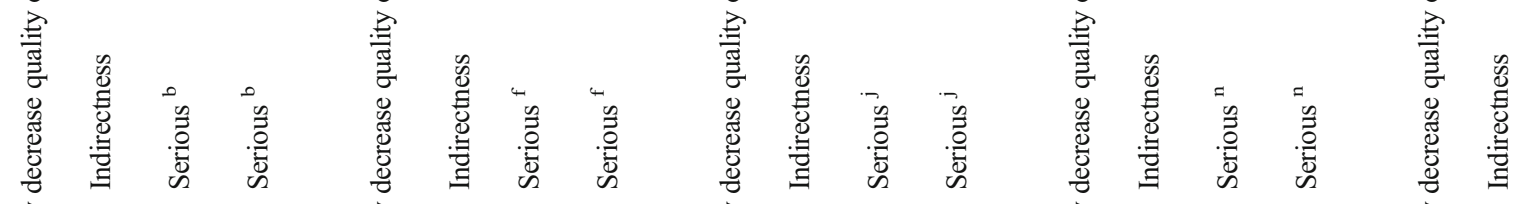

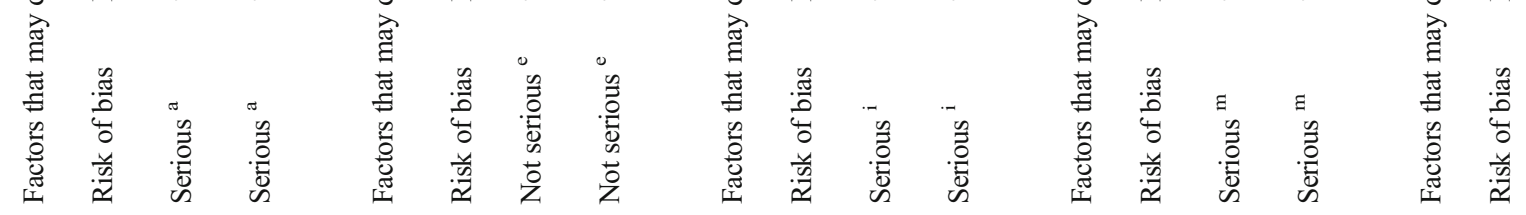

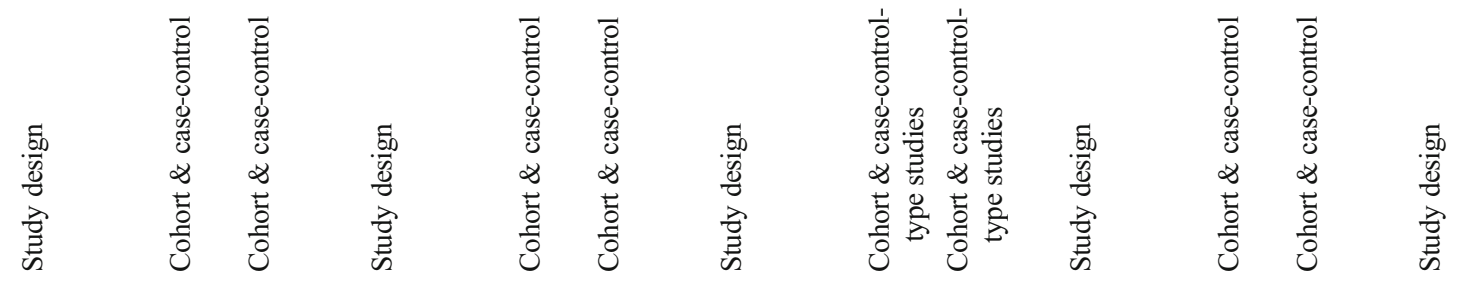

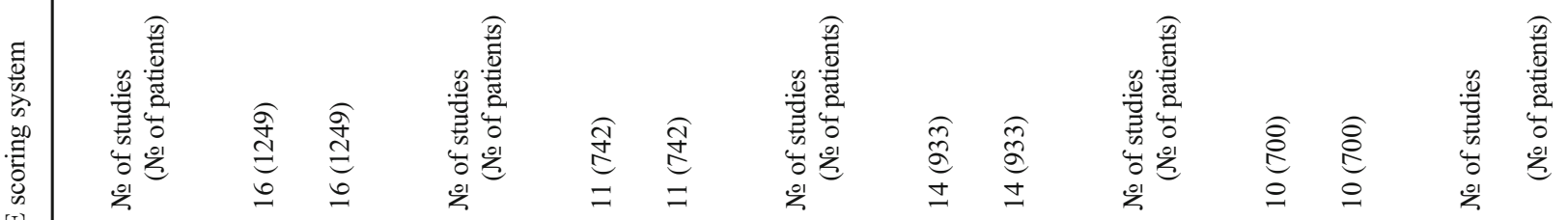

넹

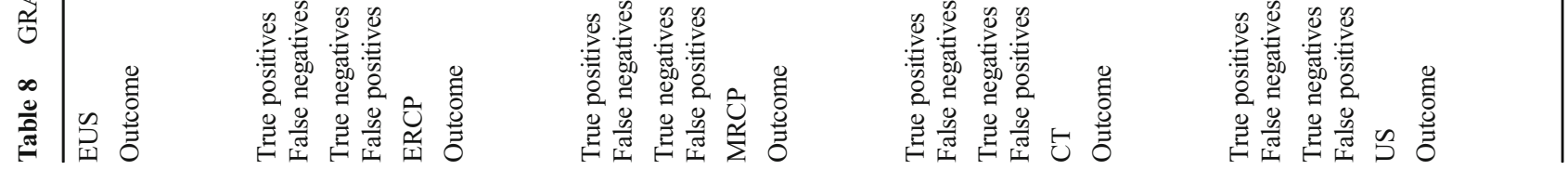




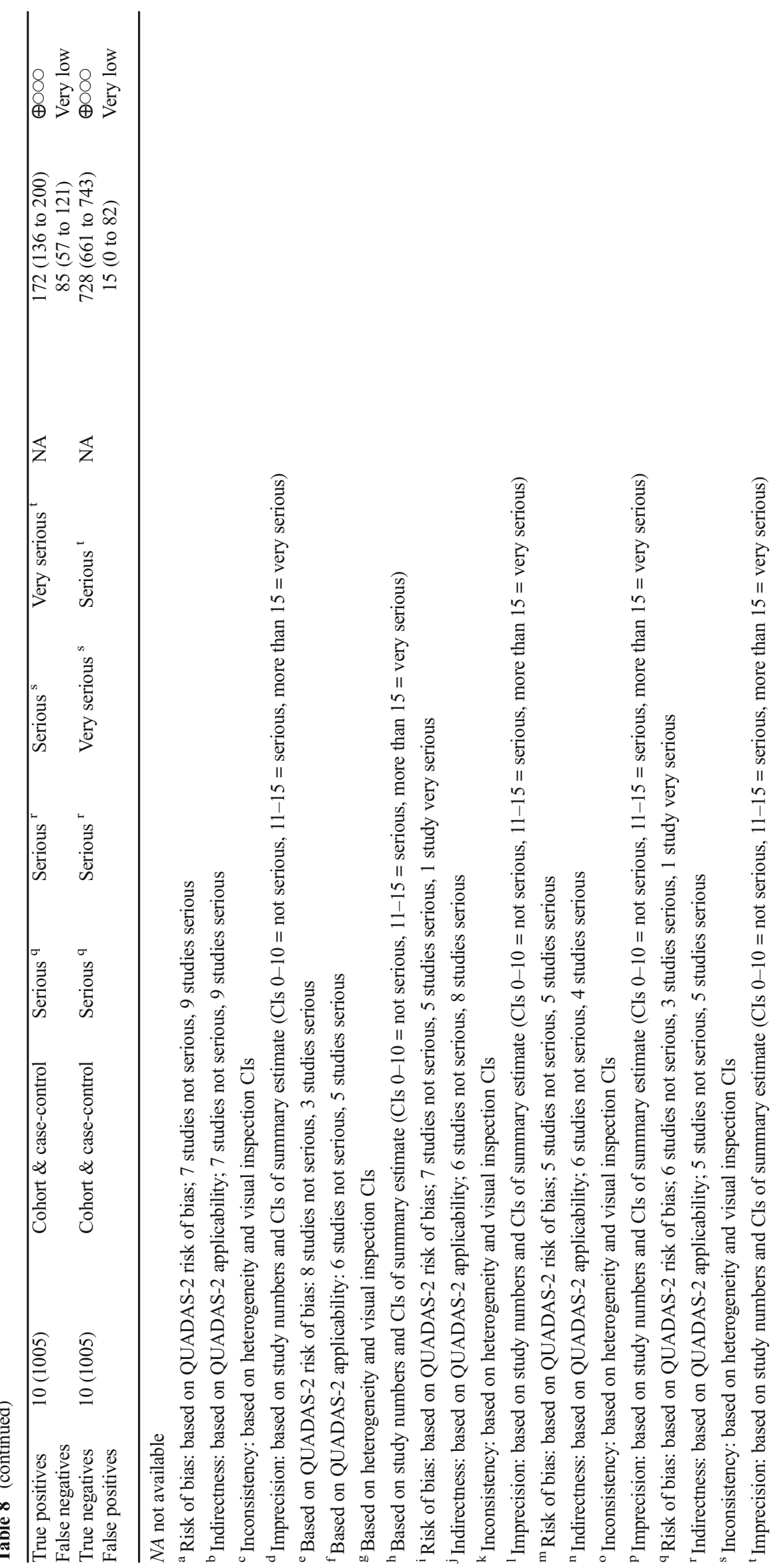


Table 9 GRADE characteristics for each study

\begin{tabular}{|c|c|c|c|c|c|c|}
\hline Modality & Name first author & Risk of bias & Indirectness & Inconsistency & Imprecision & Publication bias \\
\hline EUS & $\begin{array}{l}\text { Albashir et al } \\
\text { Brand et al } \\
\text { Buscail et al } \\
\text { Catalano et al } \\
\text { Chong et al } \\
\text { Conwell et al } \\
\text { Giovannini et al } \\
\text { Glasbrenner et al } \\
\text { Lin et al } \\
\text { Nattermann et al } \\
\text { Pungpapong et al } \\
\text { Pungpapong et al } \\
\text { Stevens et al } \\
\text { Tox et al } \\
\text { Trikudanathan et al } \\
\text { Wiersema et al }\end{array}$ & $\begin{array}{l}\text { Low } \\
\text { Serious } \\
\text { Serious } \\
\text { Low } \\
\text { Low } \\
\text { Serious } \\
\text { Serious } \\
\text { Low } \\
\text { Serious } \\
\text { Low } \\
\text { Low } \\
\text { Low } \\
\text { Serious } \\
\text { Serious } \\
\text { Serious } \\
\text { Serious }\end{array}$ & $\begin{array}{l}\text { Low } \\
\text { Serious } \\
\text { Serious } \\
\text { Low } \\
\text { Low } \\
\text { Serious } \\
\text { Serious } \\
\text { Low } \\
\text { Serious } \\
\text { Serious } \\
\text { Low } \\
\text { Low } \\
\text { Serious } \\
\text { Low } \\
\text { Serious } \\
\text { Serious }\end{array}$ & $\begin{array}{l}\text { Sensitivity: very serious } \\
\text { Specificity: serious }\end{array}$ & $\begin{array}{l}\text { Sensitivity: very serious } \\
\text { Specificity: serious }\end{array}$ & Not assessed \\
\hline ERCP & $\begin{array}{l}\text { Adamek et al } \\
\text { Buscail et al } \\
\text { Gebel et al } \\
\text { Glasbrenner et al } \\
\text { Gmelin et al } \\
\text { Lammer et al } \\
\text { Lawson et al } \\
\text { Parsi et al } \\
\text { Scarabino et al } \\
\text { Swobodnik et al } \\
\text { Triller et al }\end{array}$ & $\begin{array}{l}\text { Low } \\
\text { Low } \\
\text { Low } \\
\text { Low } \\
\text { Low } \\
\text { Serious } \\
\text { Low } \\
\text { Low } \\
\text { Serious } \\
\text { Low } \\
\text { Serious }\end{array}$ & $\begin{array}{l}\text { Low } \\
\text { Serious } \\
\text { Low } \\
\text { Low } \\
\text { Serious } \\
\text { Serious } \\
\text { Low } \\
\text { Low } \\
\text { Serious } \\
\text { Low } \\
\text { Serious }\end{array}$ & $\begin{array}{l}\text { Sensitivity: serious } \\
\text { Specificity: serious }\end{array}$ & $\begin{array}{l}\text { Sensitivity: serious } \\
\text { Specificity: serious }\end{array}$ & Not assessed \\
\hline MRCP & $\begin{array}{l}\text { Adamek et al } \\
\text { Alcaraz et al } \\
\text { Balci et al } \\
\text { Bolog et al } \\
\text { Fusari et al } \\
\text { Hellerhoff et al } \\
\text { Pamos et al } \\
\text { Pungpapong et al } \\
\text { Rudowicz-Pietruszewska } \\
\text { Sai et al } \\
\text { Schlaudraff et al } \\
\text { Sverko et al } \\
\text { Zhang et al } \\
\text { Zuccaro et al }\end{array}$ & $\begin{array}{l}\text { Low } \\
\text { Low } \\
\text { Serious } \\
\text { Serious } \\
\text { Low } \\
\text { Low } \\
\text { Low } \\
\text { Low } \\
\text { Serious } \\
\text { Serious } \\
\text { Low } \\
\text { Serious } \\
\text { Very serious } \\
\text { Serious }\end{array}$ & $\begin{array}{l}\text { Low } \\
\text { Serious } \\
\text { Serious } \\
\text { Serious } \\
\text { Low } \\
\text { Low } \\
\text { Serious } \\
\text { Low } \\
\text { Serious } \\
\text { Low } \\
\text { Low } \\
\text { Serious } \\
\text { Serious } \\
\text { Serious }\end{array}$ & $\begin{array}{l}\text { Sensitivity: serious } \\
\text { Specificity: serious }\end{array}$ & $\begin{array}{l}\text { Sensitivity: very serious } \\
\text { Specificity: not serious }\end{array}$ & Not assessed \\
\hline $\mathrm{CT}$ & $\begin{array}{l}\text { Buscail et al } \\
\text { Dramaix et al } \\
\text { Fusari et al } \\
\text { Gmelin et al } \\
\text { Imdahl et al } \\
\text { Lammer et al } \\
\text { Pistolesi et al } \\
\text { Savarino et al } \\
\text { Scarabino et al } \\
\text { Swobodnik et al }\end{array}$ & $\begin{array}{l}\text { Low } \\
\text { Low } \\
\text { Low } \\
\text { Low } \\
\text { Serious } \\
\text { Serious } \\
\text { Low } \\
\text { Serious } \\
\text { Serious } \\
\text { Low }\end{array}$ & $\begin{array}{l}\text { Serious } \\
\text { Low } \\
\text { Low } \\
\text { Serious } \\
\text { Low } \\
\text { Serious } \\
\text { Low } \\
\text { Low } \\
\text { Serious } \\
\text { Low }\end{array}$ & $\begin{array}{l}\text { Sensitivity: serious } \\
\text { Specificity: serious }\end{array}$ & $\begin{array}{l}\text { Sensitivity: very serious } \\
\text { Specificity: serious }\end{array}$ & Not assessed \\
\hline US & $\begin{array}{l}\text { Buscail et al } \\
\text { Dramaix et al } \\
\text { Gebel et al } \\
\text { Gmelin et al } \\
\text { Kremer et al } \\
\text { Lawson et al } \\
\text { Lees et al } \\
\text { Lin et al } \\
\text { Scarabino et al } \\
\text { Swobodnik et al }\end{array}$ & $\begin{array}{l}\text { Low } \\
\text { Low } \\
\text { Low } \\
\text { Low } \\
\text { Very serious } \\
\text { Low } \\
\text { Serious } \\
\text { Serious } \\
\text { Serious } \\
\text { Low }\end{array}$ & $\begin{array}{l}\text { Serious } \\
\text { Low } \\
\text { Low } \\
\text { Serious } \\
\text { Serious } \\
\text { Low } \\
\text { Low } \\
\text { Serious } \\
\text { Serious } \\
\text { Low }\end{array}$ & $\begin{array}{l}\text { Sensitivity: serious } \\
\text { Specificity: very serious }\end{array}$ & $\begin{array}{l}\text { Sensitivity: very serious } \\
\text { Specificity: serious }\end{array}$ & Not assessed \\
\hline
\end{tabular}




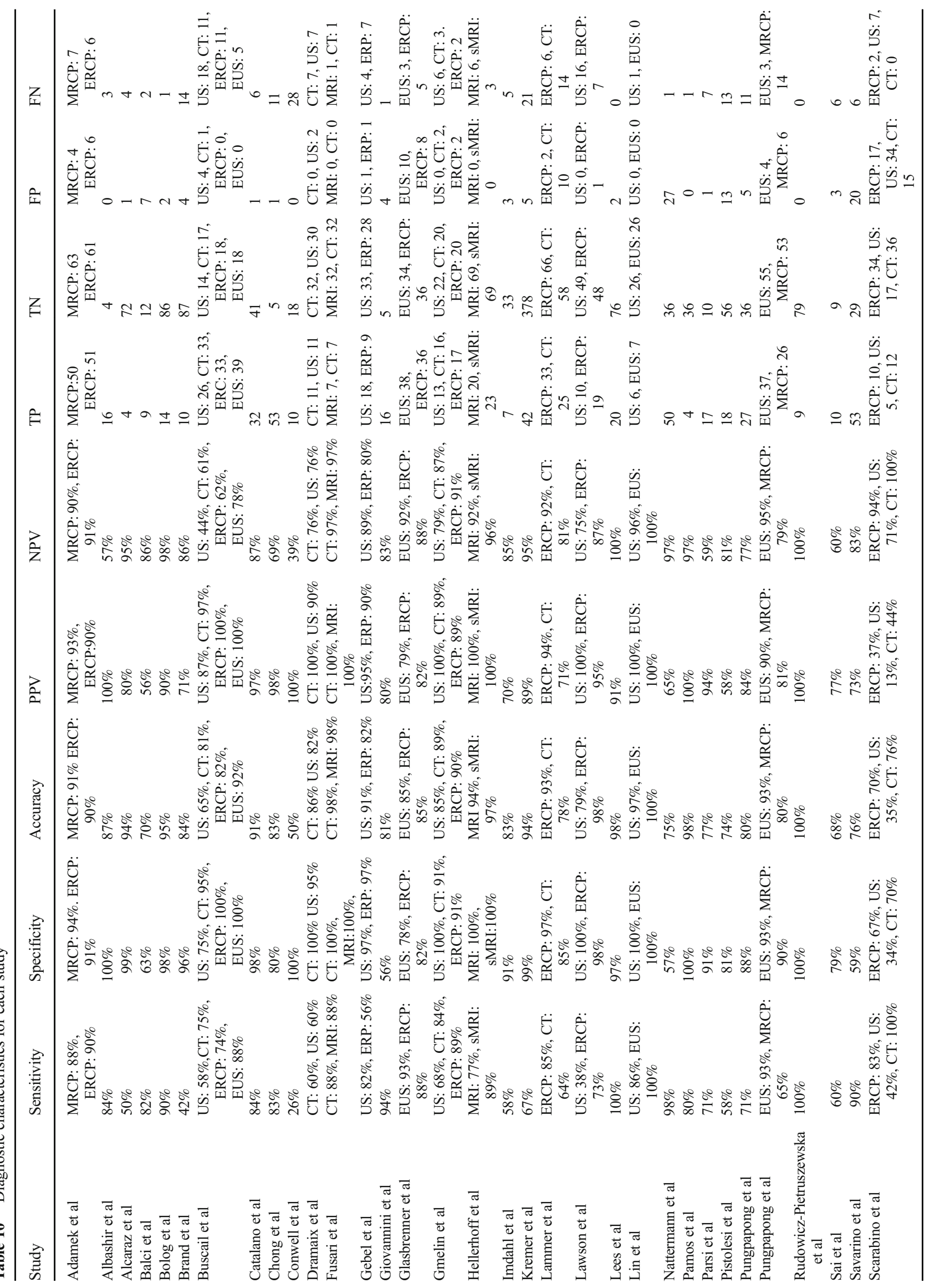




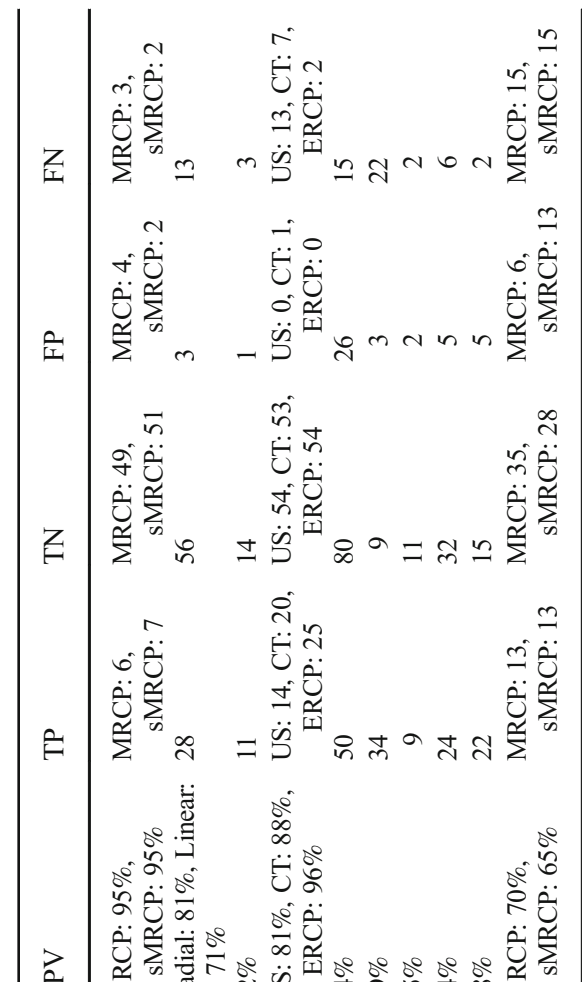

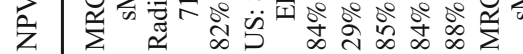

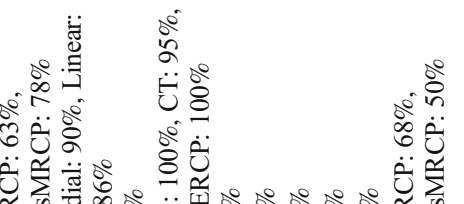

之

迥 \& 8

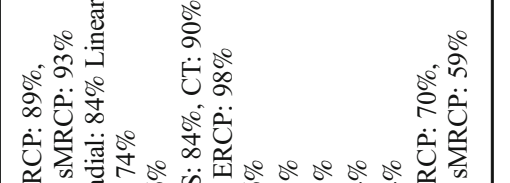

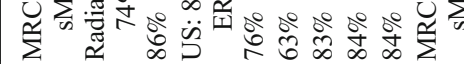

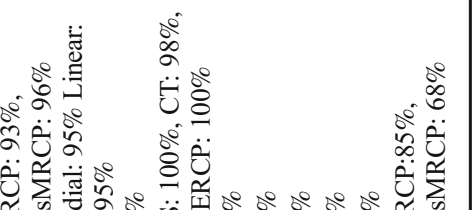

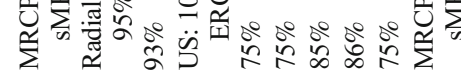

䎹 造

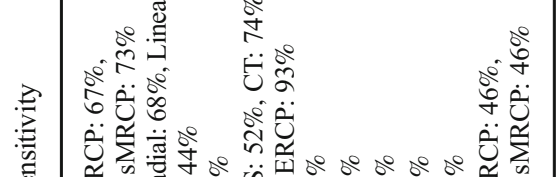

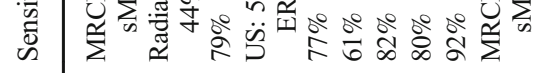

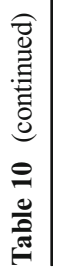

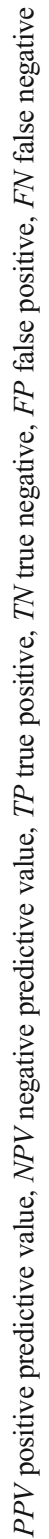

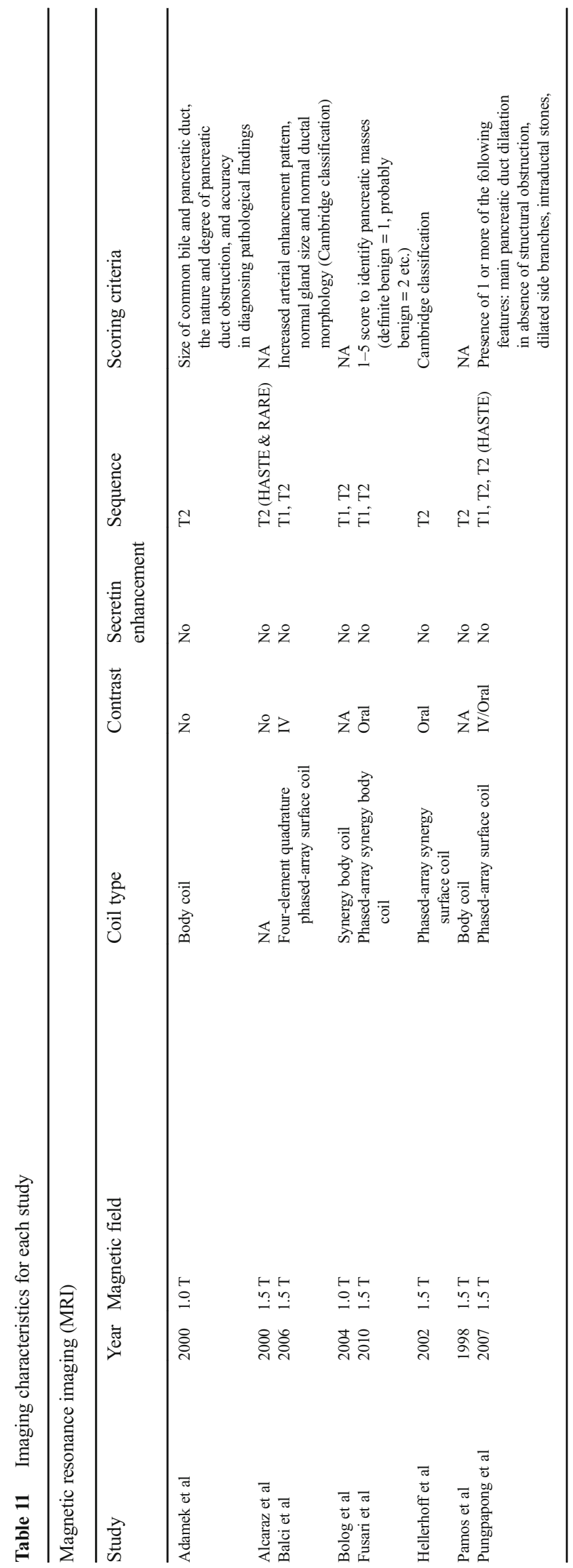




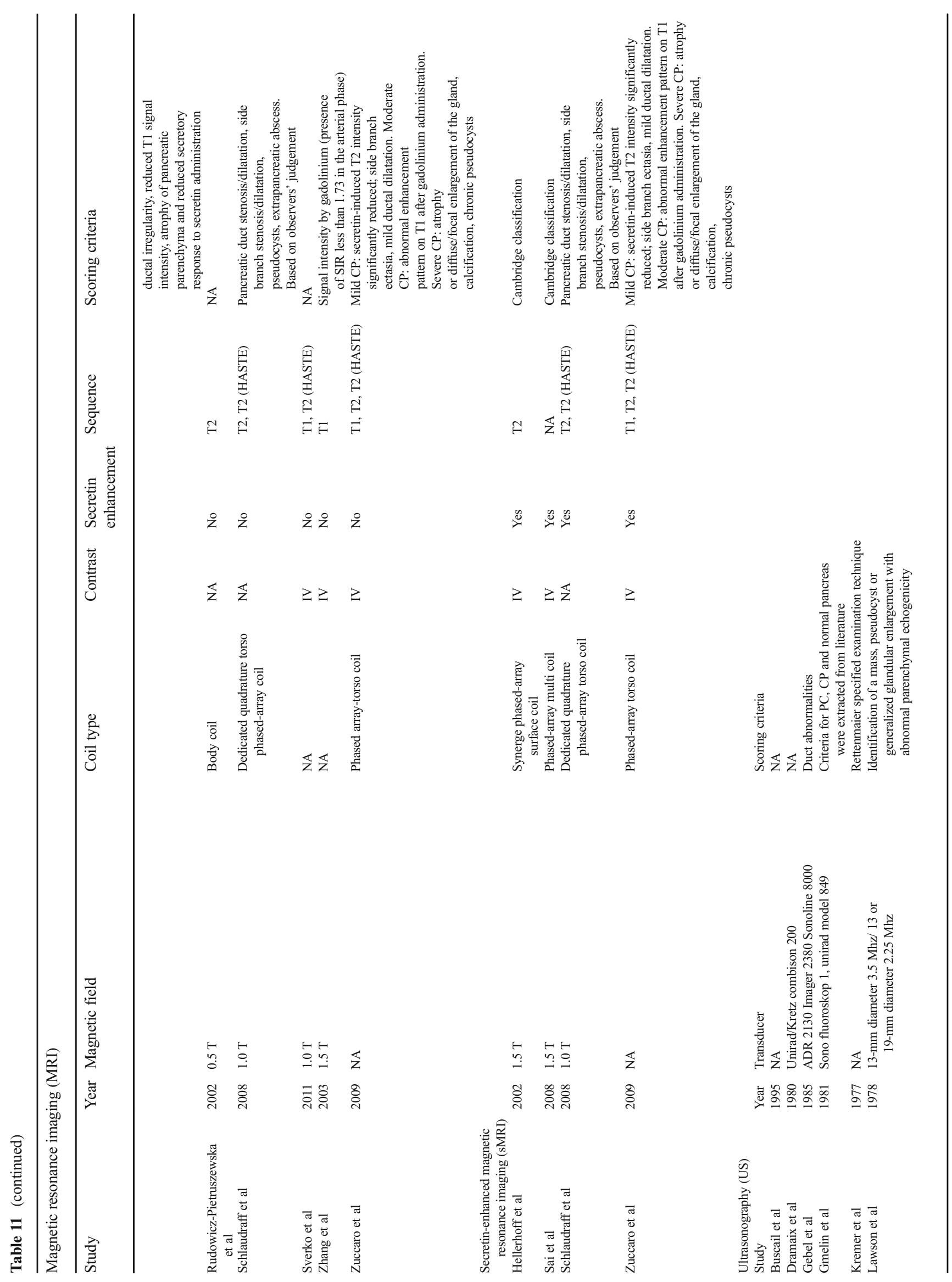




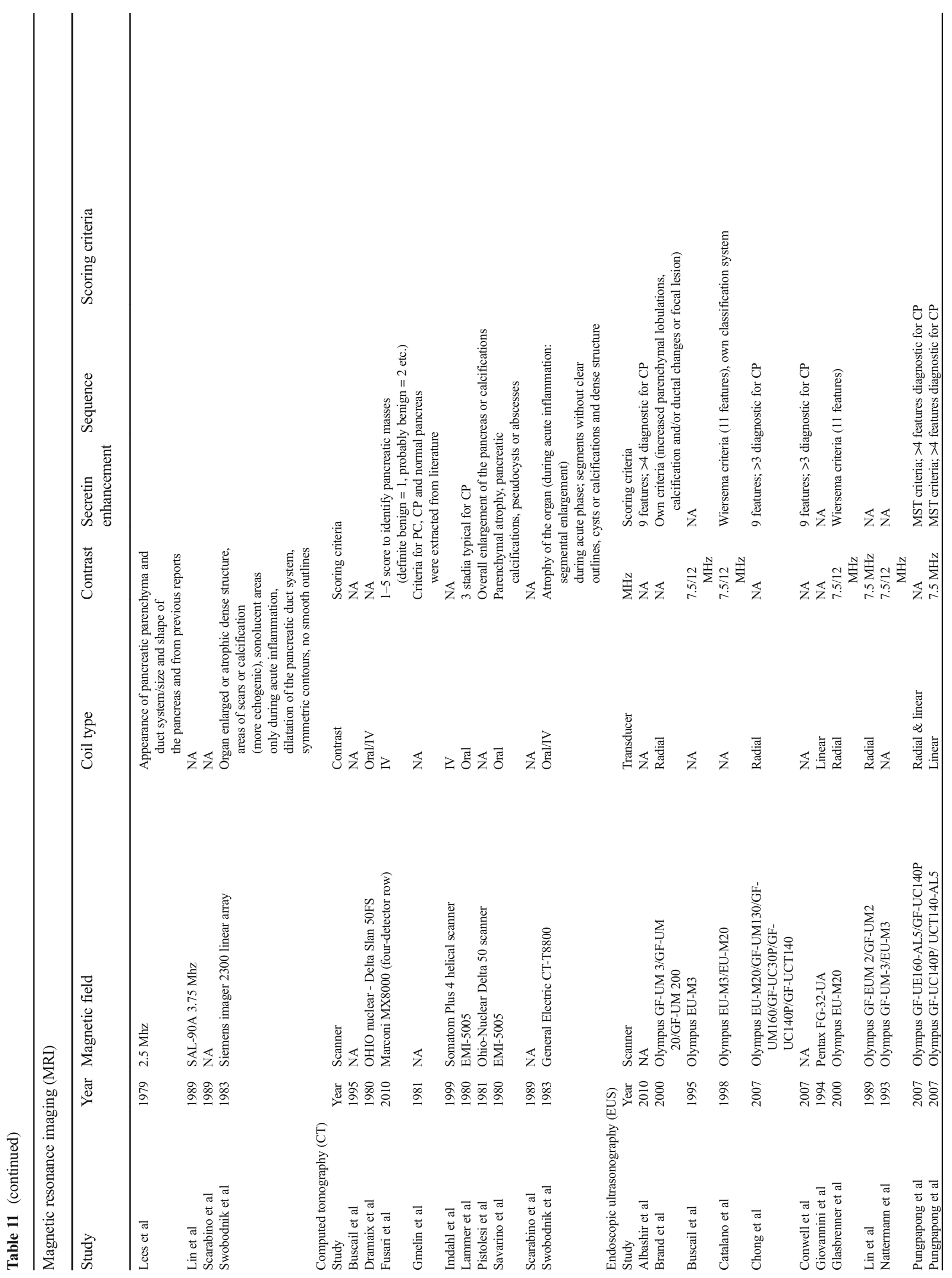




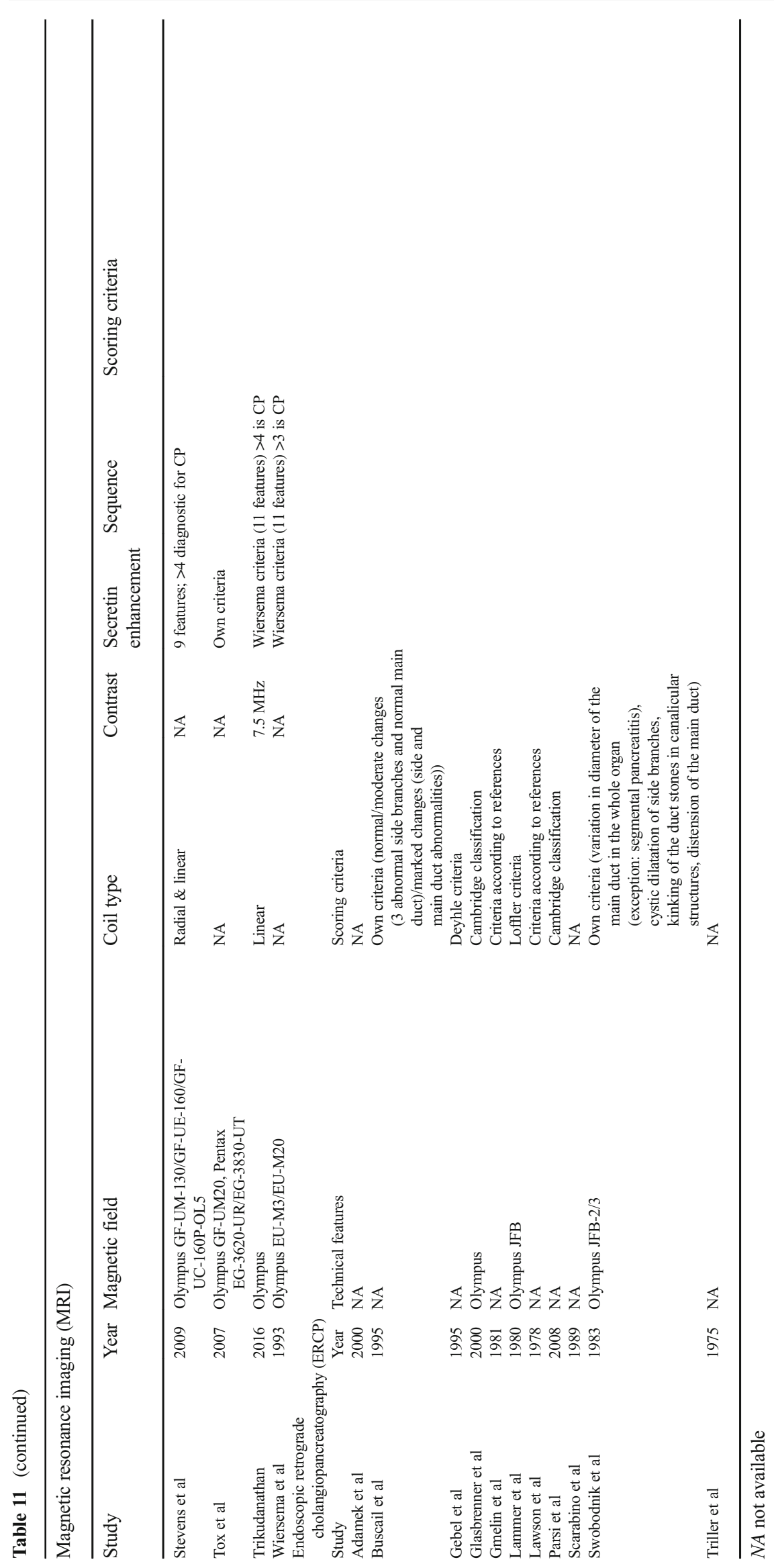


Open Access This article is distributed under the terms of the Creative Commons Attribution 4.0 International License (http:// creativecommons.org/licenses/by/4.0/), which permits unrestricted use, distribution, and reproduction in any medium, provided you give appropriate credit to the original author(s) and the source, provide a link to the Creative Commons license, and indicate if changes were made.

\section{References}

1. Gardner TB, Kennedy AT, Gelrud A et al (2010) Chronic pancreatitis and its effect on employment and health care experience: results of a prospective American multicenter study. Pancreas 39:498-501

2. Hall TC, Garcea G, Webb MA, Al-Leswas D, Metcalfe MS, Dennison AR (2014) The socio-economic impact of chronic pancreatitis: a systematic review. J Eval Clin Pract 20:203-207

3. Mullady DK, Yadav D, Amann ST et al (2011) Type of pain, painassociated complications, quality of life, disability and resource utilisation in chronic pancreatitis: a prospective cohort study. Gut 60:77-84

4. Olesen SS, Juel J, Nielsen AK, Frokjaer JB, Wilder-Smith OH, Drewes AM (2014) Pain severity reduces life quality in chronic pancreatitis: implications for design of future outcome trials. Pancreatology 14:497-502

5. Buchler MW, Martignoni ME, Friess H, Malfertheiner P (2009) A proposal for a new clinical classification of chronic pancreatitis. BMC Gastroenterol 9:93

6. Schneider A, Lohr JM, Singer MV (2007) The M-ANNHEIM classification of chronic pancreatitis: introduction of a unifying classification system based on a review of previous classifications of the disease. J Gastroenterol 42:101-119

7. Whiting PF, Rutjes AW, Westwood ME et al (2011) QUADAS-2: a revised tool for the quality assessment of diagnostic accuracy studies. Ann Intern Med 155:529-536

8. Brozek JL, Akl EA, Jaeschke R et al (2009) Grading quality of evidence and strength of recommendations in clinical practice guidelines: Part 2 of 3 The GRADE approach to grading quality of evidence about diagnostic tests and strategies. Allergy 64:1109-1116

9. Guyatt GH, Oxman AD, Vist GE et al (2008) GRADE: an emerging consensus on rating quality of evidence and strength of recommendations. BMJ 336:924-926

10. Schünemann H BJ, Guyatt G, Oxman A (2013) Handbook for grading the quality of evidence and the strength of recommendations using the GRADE approach. The GRADE Working Group; 2013. Available at: www.guidelinedevelopment.org/handbook. Accessed 28 Jan 2015

11. Higgins JP, Thompson SG, Deeks JJ, Altman DG (2003) Measuring inconsistency in meta-analyses. BMJ 327:557-560

12. Reitsma JB, Glas AS, Rutjes AW, Scholten RJ, Bossuyt PM, Zwinderman AH (2005) Bivariate analysis of sensitivity and specificity produces informative summary measures in diagnostic reviews. J Clin Epidemiol 58:982-990

13. Moher D, Liberati A, Tetzlaff J, Altman DG, Group P (2009) Preferred reporting items for systematic reviews and meta-analyses: the PRISMA statement. Ann Intern Med 151:W264

14. Adamek HE, Albert J, Breer H, Weitz M, Schilling D, Riemann JF (2000) Pancreatic cancer detection with magnetic resonance cholangiopancreatography and endoscopic retrograde cholangiopancreatography: a prospective controlled study. Lancet 356:190-193

15. Albashir S, Bronner MP, Parsi MA, Walsh RM, Stevens T (2010) Endoscopic ultrasound, secretin endoscopic pancreatic function test, and histology: correlation in chronic pancreatitis. Am J Gastroenterol 105:2498-2503

16. Alcaraz MJ, De la Morena EJ, Polo A, Ramos A, De la Cal MA, Gonzalez MA (2000) A comparative study of magnetic resonance cholangiography and direct cholangiography. Rev Esp Enferm Dig 92:427-438

17. Balci NC, Alkaade S, Akduman IE, Bilgin M, Murdock CP, Burton FR (2006) Serial contrast-enhanced MRI of the pancreas. Correlation with secretin-stimulated endoscopic pancreatic function test. Acad Radiol 13:1367-1372

18. Bolog N, Constantinescu G, Oancea I et al (2004) Magnetic resonance imaging of bile and pancreatic ducts: a retrospective study. Rom J Gastroenterol 13:91-97

19. Brand B, Pfaff T, Binmoeller KF et al (2000) Endoscopic ultrasound for differential diagnosis of focal pancreatic lesions, confirmed by surgery. Scand J Gastroenterol 35:1221-1228

20. Buscail L, Escourrou J, Moreau J et al (1995) Endoscopic ultrasonography in chronic pancreatitis: a comparative prospective study with conventional ultrasonography, computed tomography, and ERCP. Pancreas 10:251-257

21. Catalano MF, Geenen JE (1998) Diagnosis of chronic pancreatitis by endoscopic ultrasonography. Endoscopy 30:A111-A115

22. Chong AK, Hawes RH, Hoffman BJ, Adams DB, Lewin DN, Romagnuolo J (2007) Diagnostic performance of EUS for chronic pancreatitis: a comparison with histopathology. Gastrointest Endosc 65:808-814

23. Conwell DL, Zuccaro G, Purich E et al (2007) Comparison of endoscopic ultrasound chronic pancreatitis criteria to the endoscopic secretin-stimulated pancreatic function test. Dig Dis Sci 52: 1206-1210

24. Dramaix JP, Sahel J, Corbeau A (1980) A prospective comparative study of different methods of morphological examination of the pancreas. Place of ultrasonography and computerized tomography. Acta Endoscopica 10:1

25. Fusari M, Maurea S, Imbriaco M et al (2010) Comparison between multislice CT and MR imaging in the diagnostic evaluation of patients with pancreatic masses. Radiol Med 115:453-466

26. Gebel M, Stiehl M, Freise J (1985) Value of ultrasonographic imaging of the pancreas for diagnosis of chronic pancreatitis and pancreas carcinoma in comparison with ERP. Ultraschall in der Medizin 6:127-130

27. Giovannini M, Seitz JF (1994) Endoscopic ultrasonography with a linear-type echoendoscope in the evaluation of 94 patients with pancreatobiliary disease. Endoscopy 26:579-585

28. Glasbrenner B, Schwarz M, Pauls S, Preclik G, Beger HG, Adler G (2000) Prospective comparison of endoscopic ultrasound and endoscopic retrograde cholangiopancreatography in the preoperative assessment of masses in the pancreatic head. Dig Surg 17:468-474

29. Gmelin E, Weiss H-D, Fuchs H-D, Reiser M (1981) A comparison of the diagnostic accuracy of ultrasound, computer tomography and ERPC in chronic pancreatitis and carcinoma of the pancreas. Röfo 134:136-141

30. Hellerhoff KJ, Helmberger IH, Rosch T, Settles MR, Link TM, Rummeny EJ (2002) Dynamic MR pancreatography after secretin administration: image quality and diagnostic accuracy. Am J Roentgenol 179:121-129

31. Imdahl A, Nitzsche E, Krautmann F et al (1999) Evaluation of positron emission tomography with 2 - [18F]fluoro-2-deoxy-D-glucose for the differentiation of chronic pancreatitis and pancreatic cancer. Br J Surg 86:194-199

32. Kremer H, Kellner E, Schierl W, Schumm C, Weidenhiller S, Zollner N (1977) Echographic diagnosis of the pancreas. Catamnesis of 481 cases (author's transl). MMW MunchMed Wochenschr 119:1449-1452

33. Lammer J, Lepuschutz H, Sager WD, Kratochvil P, Brandstatter G, Zalaudek G (1980) Endoscopic retrograde cholangio- 
pancreaticography (ERCP) and computer tomography in the diagnosis of chronic pancreatitis, pseudocysts and carcinoma of the pancreas-a comparison (author's transl). Rontgenblatter 33:602-611

34. Lawson TL, Irani SK, Stock M (1978) Detection of pancreatic pathology by ultrasonography and endoscopic retrograde cholangiopancreatography. Gastrointest Radiol 3:335-341

35. Lees WR, Vallon AG, Denyer ME et al (1979) Prospective study of ultrasonography in chronic pancreatic disease. Br Med J 1:162-164

36. Lin JT, Wang JT, Wang TH (1989) The diagnostic value of endoscopic ultrasonography in pancreatic disorders. Taiwan Yi Xue Hui Za Zhi 88:483-487

37. Nattermann C, Goldschmidt AJW, Dancygier H (1993) Endosonography in chronic pancreatitis - a comparison between endoscopic retrograde pancreatography and endoscopic ultrasonography. Endoscopy 25:565-570

38. Pamos S, Rivera P, Canelles P et al (1998) Magnetic resonance cholangiopancreatography (MRCP) versus endoscopic retrograde cholangiopancreatography (ERCP): diagnostic usefulness. Gastroenterol Hepatol 21:174-180

39. Parsi MA, Conwell DL, Zuccaro G et al (2008) Findings on endoscopic retrograde cholangiopancreatography and pancreatic function test in suspected chronic pancreatitis and negative crosssectional imaging. Clin Gastroenterol Hepatol 6:1432-1436

40. Pistolesi GF, Procacci C, Fugazzola C (1981) Place of computed tomography in pancreatic disease. Comparison with other radiological methods. Comput Tomogr 5:115-137

41. Pungpapong S, Noh KW, Woodward TA, Wallace MB, Al-Haddad M, Raimondo M (2007) Endoscopic ultrasound and IL-8 in pancreatic juice to diagnose chronic pancreatitis. Pancreatology 7:491-496

42. Pungpapong S, Wallace MB, Woodward TA, Noh KW, Raimondo M (2007) Accuracy of endoscopic ultrasonography and magnetic resonance cholangiopancreatography for the diagnosis of chronic pancreatitis: a prospective comparison study. J Clin Gastroenterol 41:88-93

43. Rudowicz-Pietruszewska B, Sasiadek M, Jamrozik-Kruk Z (2002) MRCP with mid-field unit versus ERCP - comparison of 88 cases. Gastroenterol Pol 9:51-58

44. Sai JK, Suyama M, Kubokawa Y, Watanabe S (2008) Diagnosis of mild chronic pancreatitis (Cambridge classification): comparative study using secretin injection-magnetic resonance cholangiopancreatography and endoscopic retrograde pancreatography. World J Gastroenterol 14:1218-1221

45. Savarino V, Mansi C, Macchia G (1980) Computed tomography in the diagnosis of pancreatic diseases. Ital J Gastroenterol 12:265269

46. Scarabino T, Petronelli S, Palladino D et al (1989) ERCP in the diagnosis of bilio-pancreatic pathology. Comparison with echography and CT. Radiol Med 77:650-654

47. Schlaudraff E, Wagner H-J, Klose KJ, Heverhagen JT (2008) Prospective evaluation of the diagnostic accuracy of secretinenhanced magnetic resonance cholangiopancreaticography in suspected chronic pancreatitis. Magn Reson Imaging 26:13671373

48. Stevens T, Zuccaro G, Dumot JA et al (2009) Prospective comparison of radial and linear endoscopic ultrasound for diagnosis of chronic pancreatitis. Endoscopy 41:836-841

49. Sverko A, Tripalo-Batos A, Marotti M, Mustapic M, Beslin MB, Kruslin B (2011) Correlation between magnetic resonance imaging and histopathology in differentiation of pancreatic diseases. Acta Clin Croat 50:137-144

50. Swobodnik W, Meyer W, Brecht KD (1983) Ultrasound, computed tomography and endoscopic retrograde cholangiopancreatography in the morphologic diagnosis of pancreatic disease. Klin Wochenschr 61:291-296
51. Tox U, Hackenberg R, Stelzer A et al (2007) Endosonographic diagnosis of solid pancreatic tumors: a retrospective analysis from a tertiary referral center. Z Gastroenterol 45:307-312

52. Triller J, Voegeli E, Halter F (1975) Selective pancreatic angiography and retrograde pancreatic cholangiography as a combined examination. Röfo 122:138-144

53. Wiersema MJ, Hawes RH, Lehman GA, Kochman ML, Sherman S, Kopecky KK (1993) Prospective evaluation of endoscopic ultrasonography and endoscopic retrograde cholangiopancreatography in patients with chronic abdominal pain of suspected pancreatic origin. Endoscopy 25:555-564

54. Zhang XM, Shi H, Parker L, Dohke M, Holland GA, Mitchell DG (2003) Suspected early or mild chronic pancreatitis: enhancement patterns on gadolinium chelate dynamic MRI. Magnetic resonance imaging. J Magn Reson Imaging 17:86-94

55. Zuccaro P, Stevens T, Repas K et al (2009) Magnetic resonance cholangiopancreatography reports in the evaluation of chronic pancreatitis: a need for quality improvement. Pancreatology 9:764-769

56. Trikudanathan G, Vega-Peralta J, Malli A et al (2016) Diagnostic performance of endoscopic ultrasound (EUS) for non-calcific chronic pancreatitis (NCCP) based on histopathology. Am J Gastroenterol 111:568-574

57. Delhaye M, Van SW, Cesmeli E et al (2014) Belgian consensus on chronic pancreatitis in adults and children: statements on diagnosis and nutritional, medical, and surgical treatment. Acta Gastroenterol Belg 77:47-65

58. Frulloni L, Falconi M, Gabbrielli A et al (2010) Italian consensus guidelines for chronic pancreatitis. Dig Liver Dis 42:S381-S406

59. Martinez J, Abad-Gonzalez A, Aparicio JR et al (2013) The Spanish Pancreatic Club recommendations for the diagnosis and treatment of chronic pancreatitis: part 1 (diagnosis). Pancreatology 13:8-17

60. Schreyer AG, Jung M, Riemann JF et al (2014) S3 guideline for chronic pancreatitis - diagnosis, classification and therapy for the radiologist. Röfo 186:1002-1008

61. Remedios D, Hierath $\mathrm{M}$, Ashford $\mathrm{N}$ et al (2014) Imaging referral guidelines in Europe: now and in the future-EC Referral Guidelines Workshop Proceedings. Insights Imaging 5:9-13

62. Remedios D, Hierath M, Ashford N et al (2014) European survey on imaging referral guidelines. Insights Imaging 5:15-23

63. Remedios DCP, Ashford N, Grenier P (2014) Referral guidelines for medical imaging - availability and use in the European Union. European Union. doi:10.2833/18118

64. Clave P, Boadas J, Gonzalez-Carro P et al (1999) Accuracy of imaging techniques and tumor markers in the diagnosis of pancreatic cancer. Gastroenterol Hepatol 22:335-341

65. Orti E, Canelles P, Tome A et al (1993) Diagnostic value of aspiration cytology with ERCP. Rev Esp Enferm Dig 84: $173-177$

66. Wang LW, Li ZS, Li SD, Jin ZD, Zou DW, Chen F (2009) Prevalence and clinical features of chronic pancreatitis in China: a retrospective multicenter analysis over 10 years. Pancreas 38:248-254

67. Andriulli A, Loperfido S, Napolitano G et al (2007) Incidence rates of post-ERCP complications: a systematic survey of prospective studies. Am J Gastroenterol 102:1781-1788

68. Barthet M, Lesavre N, Desjeux A et al (2002) Complications of endoscopic sphincterotomy: results from a single tertiary referral center. Endoscopy 34:991-997

69. Cotton PB, Garrow DA, Gallagher J, Romagnuolo J (2009) Risk factors for complications after ERCP: a multivariate analysis of 11,497 procedures over 12 years. Gastrointest Endosc 70:80-88

70. Kim DH, Pickhardt PJ (2007) Radiologic assessment of acute and chronic pancreatitis. Surg Clin North Am 87:1341-1358 
71. Matos C, Bali MA, Delhaye M, Deviere J (2006) Magnetic resonance imaging in the detection of pancreatitis and pancreatic neoplasms. Best Pract Res Clin Gastroenterol 20:157-178

72. Remer EM, Baker ME (2002) Imaging of chronic pancreatitis. Radiol Clin North Am 40:1229-1242

73. Ly JN, Miller FH (2002) MR imaging of the pancreas: a practical approach. Radiol Clin North Am 40:1289-1306

74. Robinson PJA, Sheridan MB (2000) Pancreatitis: computed tomography and magnetic resonance imaging. Eur Radiol 10: 401-408
75. Ahmed Ali U, Nieuwenhuijs VB, van Eijck CH et al (2012) Clinical outcome in relation to timing of surgery in chronic pancreatitis: a nomogram to predict pain relief. Arch Surg 147:925-932

76. Ahmed Ali U, Issa Y, Bruno MJ et al (2013) Early surgery versus optimal current step-up practice for chronic pancreatitis (ESCAPE): design and rationale of a randomized trial. BMC Gastroenterol 13:49 